\title{
Effects of Neonicotinoid Seed Treatments on Phyllosphere and Soil Bacterial Communities Over Time
}

Mona Parizadeh ( $\sim$ monaparizadeh@gmail.com )

Agriculture and Agri-Food Canada https://orcid.org/0000-0002-0567-7673

Benjamin Mimee

Agriculture and Agri-Food Canada

Steven W. Kembel

UQAM Département des sciences biologiques: Universite du Quebec a Montreal Departement des Sciences Biologiques

\section{Research}

Keywords: bacterial community structure, bacterial diversity, bacterial succession, host-microbe interactions, neonicotinoid seed treatment, pesticide non-target effects, pesticide perturbation, phyllosphere, soil bacterial communities, temporal variation

Posted Date: September 17th, 2020

DOI: https://doi.org/10.21203/rs.3.rs-76081/v1

License: (c) (1) This work is licensed under a Creative Commons Attribution 4.0 International License. Read Full License 
1 Title page

2 Title

3 Effects of Neonicotinoid Seed Treatments on Phyllosphere and Soil Bacterial

4 Communities Over Time

5 Author information

6 Mona Parizadeh: monaparizadeh@gmail.com

7 Benjamin Mimee: benjamin.mimee@canada.ca

8 Steven W. Kembel: kembel.steven_w@uqam.ca

9 Author Affiliations

10 Département des sciences biologiques, Université du Québec à Montréal, 141 Avenue du

11 Président-Kennedy, Montréal, Québec, H2X 1Y4, Canada

12 Mona Parizadeh \& Steven W. Kembel

13 Agriculture and Agri-Food Canada, 430 Gouin Boulevard, Saint-Jean-sur-Richelieu, Quebec, J3B

14 3E6, Canada

15 Mona Parizadeh \& Benjamin Mimee

16 Corresponding authors

17 Correspondence to Benjamin Mimee or Steven W. Kembel.

18

19

20 


\section{Abstract}

\section{Background}

23 The phyllosphere and soil are dynamic habitats for microbial communities. Non-pathogenic

24 microbiota, including leaf and soil beneficial bacteria, plays a crucial role in plant growth and

25 health, as well as in soil fertility and organic matter production. In sustainable agriculture, it is

26 important to understand the composition of these bacterial communities, their changes in response

27 to disturbances, and their resilience to agricultural practices. Widespread pesticide application may

28 have had non-target impacts on these beneficial microorganisms. Neonicotinoids are a family of

29 systemic insecticides being vastly used to control soil and foliar pests in recent decades. A few

30 studies have demonstrated the long-term and non-target effects of neonicotinoids on

31 agroecosystem microbiota, but the generality of these findings remains unclear. In this study, we

32 used 16S rRNA gene amplicon sequencing to characterize the effects of neonicotinoid seed

33 treatment on soil and phyllosphere bacterial community diversity, composition and temporal

34 dynamics in a three-year soybean/corn rotation in Quebec, Canada.

\section{Results}

36 We found that habitat, host species and time are stronger drivers of variation in bacterial

37 composition than neonicotinoid application. They respectively explained 37.3\%, 3.2\% and 2.9\%

38 of the community variation. However, neonicotinoids did have an impact on bacterial community

39 structure, especially on the taxonomic composition of soil communities (2.6\%) and over time

40 (2.4\%). They also caused a decrease in soil alpha diversity in the middle of the growing season.

41 While the neonicotinoid treatment favored some bacterial genera known as neonicotinoid

42 biodegraders, there was a decline in the relative abundance of some potentially beneficial soil

43 bacteria, such as the plant growth-promoting rhizobacteria and the bacteria involved in the nitrogen 
44 cycle, in response to the pesticide application.

\section{Conclusions}

Our results indicate that neonicotinoids have non-target effects on phyllosphere and soil

47 bacterial communities in a soybean-corn agroecosystem, especially potentially beneficial bacteria

48 that are vital for plant growth and improve soil fertility. Exploring the interactions among bacteria

49 and other organisms, as well as the bacterial functional responses to the pesticide treatment, may

50 enhance our understanding of these non-target effects and help us adapt agricultural practices to

51 control these impacts.

53 Keywords: bacterial community structure, bacterial diversity, bacterial succession, host-microbe

54 interactions, neonicotinoid seed treatment, pesticide non-target effects, pesticide perturbation, 55 phyllosphere, soil bacterial communities, temporal variation.

\section{$57 \quad$ Background}

The phyllosphere (the aerial surfaces of plants including leaves) and soil are colonized by

59 microbial communities (microbiota), which are of great importance in the regulation of host and

60 ecosystem function. These microbial communities, including beneficial bacteria, play a crucial

61 role in plant growth promotion, decomposition and health control [1], as well as in soil fertility,

62 nitrogen fixation, and organic matter production [2, 3]. Previous studies have shown that the

63 taxonomic composition of phyllosphere bacteria is associated with host plant species identity [4-

64 6] and changes predictably during the growing season and as plant ages [7-9]. Host species were

65 found to be a more important driver of variation in phyllosphere bacterial communities than time

66 [10]. Other studies on the composition of soil bacteria have associated community variations with 
67 host plant species and growth stage [11], site [12] and time [13, 14]. Host species were also shown

68 to be a stronger driver of variation in soil bacterial communities than host plant growth stage and

69 development time [11].

70 Bacterial succession refers to the bacterial community variation patterns over time and in 71 response to environmental changes and disturbances [7]. Comparing temporal versus spatial

72 variation in bacterial community structure, the effects of time (seasonal variability) on bacterial

73 communities is often higher than habitat impacts [15]. Environmental disturbances and

74 perturbations (such as cultivation methods, drought, climate change, and pesticide treatments) can

75 also alter the bacterial community structure and composition [16, 17]. During the succession

76 process, some bacterial communities may survive by modifying their habitat, increasing their

77 abundance or becoming more resistant or resilient to disturbances [16, 18]. Hence, if a disturbance

78 is persistent, it can cause long-term changes in bacterial community structure and affect bacterial

79 succession [18]. During the last decades, the widespread application of chemical pesticides in agro-

80 ecosystems has influenced many non-target species and their succession patterns [17, 19].

81 Pesticides can change the interaction between plants and some bacteria, such as nitrogen-fixing

82 rhizobacteria, which may lead to the inhibition of nitrogen fixation [20, 21]. They can also affect

83 soil fertility and quality by impacting soil bacterial diversity and function and altering their

84 nitrification, denitrification and mineralization of organic matter [22]. In this study, to assess the

85 effects of pesticides on the phyllosphere and soil bacterial community structure and intra- and

86 inter-annual succession, we have focused on a class of the most widely used insecticide pesticides,

87 neonicotinoids.

88 Neonicotinoids (also known as neonics) are a family of systemic and neuro-active 89 insecticides, chemically similar to nicotine, that were introduced in the late 1980s [23, 24]. Like 
90 nicotine, they interrupt neural transmission in the nervous system by binding to the nicotinic

91 acetylcholine receptors (nAChRs). Because of the fundamental distinctions between the nAChRs

92 of invertebrates and vertebrates, neonicotinoids are selectively more toxic to invertebrates, like

93 insects $[25,26]$. In North America, neonicotinoids have mostly been used as seed treatments to

94 control a variety of foliar and soil early-season insect pests in corn, soybean, wheat and other

95 important crops [27-29]. These compounds are tiny molecules and are highly soluble in water

96 [30]. Given their systemic nature, plants take them up from the seed covering and translocate them

97 to different tissues and products, including nectar, guttation and pollen [31-33]. Neonicotinoids

98 may remain active from 20-30 days in soybean [34] and corn [35] to 200 days in winter wheat

99 [36]. Plants only absorb about $20 \%$ of the seed covering $[31,35]$. The rest of the pesticide persists

100 in soil for up to three years, depending on its active ingredient and the soil properties (e.g. soil

101 type, organic matter content and $\mathrm{pH}$ ) [30, 37]. During the last decades, many questions have been

102 raised about the potential impacts of the widespread and prophylactic [37, 38] use of

103 neonicotinoids on non-target organisms. Past studies have shown some negative effects of

104 neonicotinoids on agriculturally beneficial organisms, including beneficial soil invertebrates like

105 earthworms [39], and insect pollinators, particularly honeybees [28, 30, 40-42]. Although

106 neonicotinoids target organisms that possess a nervous system and the nAChRs, some studies have

107 reported that they have non-target impacts on the functions and structure of microbial

108 communities, such as fungal [43] and bacterial structure, abundance and community composition

109 in phyllosphere [43-45] and soil [46, 47]. Previous biochemical or culture-based microbiological

110 studies have also confirmed the effects of these insecticides on bacterial respiration, phosphatase

111 activity, and other enzyme activities, including ammonification, nitrification, and denitrification

$112 \quad[48-51]$. 
113 Soybean and corn are two important agricultural crops and are among those that are

114 typically treated by pesticides, including neonicotinoids. In this study, we aim to (1) characterize

115 the drivers of variation in bacterial community structure of soybean and corn phyllosphere and soil

116 and (2) identify the responses of bacterial community composition variation and diversity to

117 neonicotinoid seed treatment in a three-year soybean/corn rotation. We hypothesized that (1)

118 habitat, host species and time will all contribute to variation in bacterial community composition

119 and diversity, and (2) neonicotinoid seed treatment will cause a shift in the bacterial community

120 composition and a decrease in bacterial diversity of both phyllosphere and soil. We address these

121 objectives and hypotheses by quantifying bacterial community structure using bacterial 16S rRNA

122 gene amplicon sequencing in soybean and corn phyllosphere and soil samples collected over three

123 years in Quebec, Canada.

125 Results

126 Effects of habitat, host species and time on the phyllosphere and soil bacterial communities

127 In this experiment, the habitat (phyllosphere versus soil) was the strongest driver of

128 bacterial community variation. Habitat alone explained $37.3 \%$ of the community variation, while

129 host plant species (soybean versus corn) explained only 3.2\%, and their interaction $3.7 \%$

130 (PERMANOVA $\mathrm{P}<0.001$, Table 1). Community composition was significantly more

131 homogenous among soil samples than phyllosphere samples (average distance to median 0.42

132 versus 0.50 , ANOVA on multivariate homogeneity of groups dispersions $\mathrm{F}=24.13, \mathrm{P}<0.001$ )

133 and the phyllosphere communities exhibited less variation in corn than in soybean (average

134 distance to median 0.38 versus 0.48 , ANOVA on multivariate homogeneity of groups dispersions

$135 \mathrm{~F}=6.20, \mathrm{P}<0.05$, Fig. 1A). Bacterial alpha diversity was significantly higher in soil than in the 
136 phyllosphere (Shannon index mean \pm SE $7.0 \pm 0.02$ versus $4.2 \pm 0.10$, Wilcoxon adjusted $\mathrm{P}<$

137 0.0001). The relative abundance of several bacterial families was strongly associated with soil

138 (such as Gemmatimonadaceae and Solibacteraceae), soybean phyllosphere (such as

139 Beijerinckiaceae and Rhizobiaceae) or corn phyllosphere (such as Sphingomonadaceae and 140 Hymenobacteraceae $)(\mathrm{P}<0.001$, envfit analysis of correlation between PCoA axes and variables,

141 Fig. 1B; Supp. Tab. 1, Additional File).

Time was also a significant determinant of bacterial community variation, in particular in

143 the phyllosphere habitat. Month and year together explained $2.9 \%$ of the whole bacterial

144 community composition variation while the interactions between time, habitat and host species

145 explained $7.2 \%$ of the variation (PERMANOVA $\mathrm{P}<0.001$, Table 1 ). Time was a much greater

146 driver of community composition variation in the phyllosphere than in soil (15.7\% versus $4.6 \%$,

147 PERMANOVA $\mathrm{P}<0.001$, Table 1). Alpha diversity varied in time in the phyllosphere but not in

148 soil (Table 2). This effect in the phyllosphere was especially obvious between the first and the last

149 year of the rotation where diversity was highest in the last year (Shannon index mean \pm SE

150 respectively, $4.0 \pm 0.17$ versus $4.8 \pm 0.20$, Wilcoxon adjusted $\mathrm{P}<0.0001$, Table 2 ) but we also

151 observed intra-annual variation in diversity (Table 2).

152 Effects of neonicotinoid seed treatment on bacterial communities

153 Neonicotinoid seed treatment showed complex effects on the composition of bacterial

154 communities. Neonicotinoid treatment alone explained a small but significant portion of the

155 variation in both the phyllosphere (1.3\%) and soil $(2.6 \%)$ (PERMANOVA P $<0.01$, Table 3).

156 Since the bacterial composition varied greatly among host species and time (Table 3, Fig. 2), the

157 impacts of neonicotinoid seed treatment were partially masked by this variation. Effects of

158 neonicotinoid treatment were especially evident in soils in the middle of the growing season (Fig.

159 2C). To uncover neonicotinoid impacts, we analyzed each crop species separately, which revealed 
160 a much stronger effect of the neonicotinoid seed treatment on the composition of the phyllosphere

161 communities in corn $(5.3 \%)$ than in soybean $(1.6 \%)$ (PERMANOVA $\mathrm{P}<0.001$ and $\mathrm{P}<0.05$

162 respectively, Table 3, Fig. 3). There was no significant difference in phyllosphere alpha diversity

163 between neonicotinoid treatments overall, but soil bacterial alpha diversity was significantly

164 higher in control versus neonicotinoid-treated samples (Shannon index mean \pm SE 7.2 \pm 0.02

165 versus $7.0 \pm 0.03$, Wilcoxon adjusted $\mathrm{P}<0.001$, Table 2 ).

The overall effect of neonicotinoid seed treatment on the temporal variation of bacterial

167 community composition and alpha diversity was weak. In the phyllosphere, although there was a

168 small significant effect of the interaction between neonicotinoid application and time (month and

169 year) on variation in community composition (1.4\%, PERMANOVA P $<0.05$, Table 3), the

170 impacts on inter-annual variation and specific interactions with individual host species were not

171 significant. The interaction of neonicotinoid seed treatment and time was slightly stronger in soil,

172 especially with month $(2.4 \%$, PERMANOVA $\mathrm{P}<0.01$, Table 3$)$. Uncovering these effects by

173 studying each crop separately revealed that this month-to-month temporal variation in bacterial

174 community structure within a growing season was particularly important in corn (5.6\%,

175 PERMANOVA P $<0.05$, Table 3). Similarly, while the interaction between neonicotinoid seed

176 treatment with time had no significant effect on bacterial alpha diversity in the phyllosphere, soil

177 alpha diversity was significantly reduced in the neonicotinoid-treated samples in July and August

178 (interaction between neonicotinoid seed treatment and month: linear regression analysis of

179 Shannon index, $\mathrm{F}=6.27$, ANOVA $\mathrm{P}<0.001$; significant interactions among months and

180 treatment: Shannon index, Wilcoxon $\mathrm{P}<0.001$, Table 2).

181 Bacterial taxa impacted by neonicotinoid seed treatment

182 Neonicotinoid seed treatment led to changes in the relative abundance of some 
183 phyllosphere and soil bacterial ASVs. Overall, we detected 34 bacterial ASVs in the phyllosphere

184 and 294 in soil that were significantly differentially abundant between the control and 185 neonicotinoid-treated samples. In the phyllosphere, 22 ASVs (mainly Bacteroidetes) were more 186 abundant, and 12 (mainly Proteobacteria) were less abundant in response to neonicotinoid seed 187 treatment (Table 4). The genera Hymenobacter (13 ASVs) and Pseudomonas (4 ASVs) were

188 particularly favored by neonicotinoid treatment, while the genera Arsenophonus (4 ASVs) and 189 Skermanella (3 ASVs) among others decreased in abundance in neonicotinoid-treated samples 190 (DESeq2, Fig. 4A; Supp. Tab. 2, Additional File). In soil, 68 ASVs (mainly Actinobacteria and 191 Chloroflexi) were more abundant in the neonicotinoid-treated samples, while 226 (mainly 192 Proteobacteria) were less abundant (Table 4). More than 60 genera of soil bacteria were 193 significantly impacted by neonicotinoid treatment (Fig. 4B; Supp. Tab. 3, Additional File). Genera 194 negatively affected by neonicotinoid treatment included some of the beneficial soil bacteria (e.g. 195 Ammoniphilus, Bacillus, Bosea, Bradyrhizobium, Hyphomicrobium, Mesorhizobium, Microvirga, 196 Nitrospira, Nitrosospira, Rhizobacter and Rhodanobacter) while the genera favored by the 197 neonicotinoid treatment were dominated by Actinobacteria, including genera potentially involved 198 in neonicotinoid degradation (e.g. Mycobacterium [52] and Streptomyces [53]) or other pesticides 199 degradation (e.g. Arthrobacter [54]).

201 Discussion

202 Our findings indicate that habitat (soil versus phyllosphere), host species (soy versus corn), 203 time, and their interactions are all strong drivers of bacterial composition variation in a soybean 204 and corn agroecosystem. While this result is perhaps not surprising given that previous studies 205 have identified these factors as important drivers of phyllosphere $[5,6,55]$ and soil bacterial 206 communities $[11,13,14]$, our results suggest that complex interactions among these factors drive 
overall community composition and diversity. In particular, we have shown a role for temporal

208 variation, alone and in interaction with habitat and host species, as an important driver of bacterial

209 community composition variation, especially in the phyllosphere. While succession of microbial

210 communities in the phyllosphere has been documented previously $[7,9,56]$, here we have shown

211 that even in a rotation of annual crops, the patterns of bacterial succession within and among years

212 are an important driver of community structure.

213 We have shown that neonicotinoid seed treatments have a non-target impact on bacterial

214 community structure and diversity in a soybean/corn agroecosystem, in particular on the

215 taxonomic composition of soil bacterial communities over the growing season. Phyllosphere and

216 soil bacteria exhibit different patterns of community composition, alpha diversity and temporal

217 variation throughout the growing season and in response to neonicotinoid application. In the

218 phyllosphere, host plant species and time are stronger drivers of bacterial community variation

219 than neonicotinoid seed treatment; however, neonicotinoids interact with these parameters to

220 influence the phyllosphere bacterial community composition. Overall, soil bacteria exhibited

221 stronger changes in community composition and a significant decline in bacterial alpha diversity

222 in response to neonicotinoid treatment, while phyllosphere bacteria responses to neonicotinoids

223 were weaker. Our results complement previous lab-based studies of neonicotinoid effects on

224 bacterial communities [47, 57, 58], providing some of the first field-based evidence that 225 neonicotinoids impact bacterial diversity in agroecosystems.

226 Overall, soil bacterial communities were more affected by neonicotinoid pesticide

227 treatment than phyllosphere bacterial communities. Neonicotinoid effects on soil bacterial

228 community composition and diversity varied greatly in time, with the impacts of neonicotinoid

229 application on the soil bacterial community composition and alpha diversity most pronounced in 
230 the middle of the growing season. We suggest that this could be explained by the fact that

231 neonicotinoids' active period is much shorter in plants $[34,35]$ than in soils, where they potentially

232 persist for months or years [30, 37]. Despite the reported accumulation potential of neonicotinoids

233 in soils over time [59], we did not observe any significant inter-annual difference in bacterial

234 diversity among years in interaction with the pesticide treatment, perhaps due to degradation or

235 leaching of the neonicotinoids $[60,61]$.

236 We also observed that the more homogenous the bacterial community composition is, the

237 more it is altered by the neonicotinoid application (soil more than phyllosphere and corn

238 phyllosphere more than soybean phyllosphere). We need further studies to determine if the

239 homogeneity of the bacterial communities resulted in less resilience in response to perturbations

240 or if less variability within groups allowed us to notice more changes in the communities.

241 In addition to community-wide responses of bacteria to the neonicotinoid treatment,

242 numerous bacterial taxa increased or decreased in relative abundance in response to

243 neonicotinoids. Bacterial taxa that were favored by the pesticide treatment include several genera

244 that are known to be potentially involved in neonicotinoid degradation (e.g. Hymenobacter [62],

245 Mycobacterium [52], Pseudomonas [63], and Streptomyces [53]). In soils, there was a decline in

246 the relative abundance of several ASVs from Proteobacteria and Gemmatimonadetes phyla and an

247 increase in some ASVs from Chloroflexi and Actinobacteria, a result partially in accordance with

248 a previous study that reported a decrease in the relative abundance of Gemmatimonadetes and OD1

249 phyla and an increase in the relative abundance of the Chloroflexi and Nitrospirae phyla in

250 response to the neonicotinoid treatments [47].

251 Neonicotinoid seed treatment led to decreases in the relative abundance of several 252 potentially beneficial soil bacteria, including the plant growth-promoting rhizobacteria (PGPR) 
253 that are capable of developing a symbiotic association with host plants (e.g. Bacillus, Bosea, 254 Mesorhizobium and Rhizobacter [64]), nitrogen-fixing bacteria (e.g. Bradyrhizobium and 255 Microvirga [65]), and other bacteria involved in the nitrogen cycle (e.g. Ammoniphilus, 256 Hyphomicrobium, Nitrospira, Nitrosospira and Rhodanobacter [66]). While we did not measure

257 the effects of neonicotinoid treatments on ecosystem processes such as nitrification, our results 258 suggest a potential mechanism for the negative effects of neonicotinoids on nitrification that have 259 been observed in previous studies $[50,58]$.

\section{Conclusion}

To date, there have been few studies that have evaluated the impacts of neonicotinoid seed

263 treatment on phyllosphere and soil bacterial communities. To our knowledge, this study is the first

264 with an experimental design that represents real farming conditions in a crop rotation. Despite the

265 fact that neonicotinoids target invertebrates, we observed non-target impacts of neonicotinoids on

266 bacterial communities of the phyllosphere and soil, especially the beneficial bacteria that are

267 crucial for plant growth and health and soil fertility and quality. Future studies to identify the

268 genomic and physiological features associated with tolerance of neonicotinoids will be required to

269 understand the mechanistic reasons for these associations. Investigating the biological interactions

270 among bacteria and other micro- and macro-organisms that are affected by pesticides will help us

271 to better understand the non-target effects of pesticides on microbial diversity and how to control

272 them with better agricultural practices. 


\section{Methods}

\section{Study Site}

276 We cultivated a three-year rotation of soybean (2016 and 2018) and corn (2017) on the

277 Agriculture and Agri-Food Canada experimental farm in L'Acadie (ACA) (45¹7'38.0"N;

278 73²0'58.0"W), Quebec, Canada. L'Acadie is located in Canadian hardiness zone 5a. The region

279 is characterized by having a clay loam soil type and a temperate climate. In mid-May of each year,

280 we sowed soybean or corn on a $100 \times 30 \mathrm{~m}$ field, previously a meadow, that had not received

281 neonicotinoid application during the three years preceding the experiment. Four replicates of each

282 non-neonicotinoid (control) and neonicotinoid-treated plots (100 x $3 \mathrm{~m}$ ) were established

283 alternately and consisted of four rows each. Two extra neonicotinoid-treated plots surrounded the

284 experimental field. Soybean and corn seeds were coated with three fungicides (difenoconazole,

285 metalaxyl-M and sedaxane) in both control and treated plots. The neonicotinoid-treated seeds were

286 also covered by thiamethoxam at $0.25 \mathrm{mg} / \mathrm{seed}$. The fields were under no-till farming, and

287 glyphosate was applied twice during each growing season (before seeding and one month after it)

288 to control weeds. The corn field was also fertilized with $400 \mathrm{~kg} / \mathrm{ha}$ NPK (15-15-15) before seeding

289 and $222 \mathrm{~kg} / \mathrm{ha} \mathrm{N}$ (27.5\%) one month after seeding. Soil physicochemical properties (e.g. pH, etc.)

290 were constant across the experimental field and did not differ between the growing seasons.

\section{Sample Collection}

292 To study the phyllosphere bacteria (the bacteria collected from the leaf surface in our case),

293 each year we collected 48 samples (two samples per plot at three sampling times during the

294 growing seasons), for a total of 144 samples. The three annual sampling occasions happened in

295 July, August and September. We sampled 50-100 g of healthy mature middle leaves of 6-10 close

296 plants from the two middle rows of each plot. We then stored each sample in a sterile plastic bag 
297 and transferred it to the laboratory in a cooler, surrounded by ice packs. We immediately collected

298 the bacterial cells from the leaves by washing them in a $0.85 \%$ saline solution and agitating the

299 solution using a stomacher at $250 \mathrm{rpm}$ for $30 \mathrm{sec}$. We then transferred the solutions to $50-\mathrm{ml}$ tubes,

300 centrifuged them at 4,000 $\mathrm{g}$ for 20 minutes and discarded the supernatants. We kept the remaining

301 pellets at $-80^{\circ} \mathrm{C}$ until use.

302 To study the soil bacteria, we sampled bulk soil (soil that does not adhere to plant roots)

303 from the upper 12-15 $\mathrm{cm}$ layer of soil with a corer $(2 \mathrm{~cm}$ in diameter) from the soil around the

304 same plants that we sampled for the phyllosphere. For each soil sample, we collected soil from six

305 different spots, in a zigzag pattern and at $10 \mathrm{~cm}$ from the plants, and then mixed and pooled them

306 into one 400-500 g sample [8, 67]. We transferred samples to the laboratory in a cooler and stored

307 at $-80{ }^{\circ} \mathrm{C}$ until use. Each year, we collected 48 soil samples (two samples per plot at the same three

308 sampling times as phyllosphere), for a total of 144 samples.

309 DNA extraction

310 We extracted DNA from the samples of phyllosphere (pellets containing bacterial cells)

311 and soil (directly) using MoBio PowerSoil DNA isolation kit (QIAGEN). Considering the high

312 amount of material to be extracted from each soil sample, we extracted DNA twice, each time from

$3130.5 \mathrm{~g}$ of the same sample, and pooled the extractions together in order to better capture soil bacterial

314 community variation. The rest of the extraction was performed according to the manufacturer's

315 instructions. Then, we measured the concentration and quality of the extracted DNA using Qubit

316 (Thermo Fisher Scientific) and Nanodrop (Thermo Fisher Scientific) prior to storing them at -80

$317{ }^{\circ} \mathrm{C}$.

318 Bacterial DNA amplification

319 Following previously described protocols $[6,10,68]$, we amplified the V5-V6

320 hypervariable regions of the bacterial 16S rRNA gene, using chloroplast-excluding primers (16S 
321 primers 799F- 1115R [69, 70]). We added variable length barcodes and Illumina adaptor sequence

322 to the 5 ' end of the primers. Each PCR reaction $(25 \mu \mathrm{L})$ contained $1 \mu \mathrm{L}$ of genomic DNA (1:10

323 dilution for soil samples), $5 \mu \mathrm{L}$ 5xHF buffer (Thermo Scientific), $0.5 \mu \mathrm{L}$ dNTPs (10 mM each),

$3240.75 \mu \mathrm{L}$ DMSO, $0.25 \mu \mathrm{L}$ Phusion Hot Start II polymerase (Thermo Scientific), $1.0 \mu \mathrm{L}$ of each

325 primer $(5 \mu \mathrm{M})$, and $15.50 \mu \mathrm{L}$ double-distilled water. We amplified the bacterial DNA in an Agilent

326 SureCycler 8800 using the following conditions: $98{ }^{\circ} \mathrm{C}$ for $30 \mathrm{sec}, 35$ cycles of $98^{\circ} \mathrm{C}, 15$-sec

327 denaturation; $64{ }^{\circ} \mathrm{C}, 30$-sec annealing, and $72{ }^{\circ} \mathrm{C}, 30$-sec elongation; followed by a final elongation

328 at $72{ }^{\circ} \mathrm{C}, 10 \mathrm{~min}$. All samples were distributed randomly into several 96-well PCR plates for DNA

329 amplification. Each PCR plate contained one positive and one negative control. Each positive

330 control included Clavibacter michiganensis, Pectobacterium sp., E. coli DHS alpha, Pantoea

331 stewartii and Xanthomonas sp., while the negative controls were nuclease-free, DEPC-treated and

332 autoclaved water. We also had negative controls of the sampling plastic bags, tubes and the

333 extraction kit. All PCR products were electrophoresed on a 2\% agarose gel in 1X TAE buffer,

334 stained with AMRESCO's EZ-Vision dye as loading buffer (VWR Life Science), and visualized

335 by G:BOX gel doc (Syngene).

336 Normalization, library preparation and sequencing

337 All PCR products were normalized using SequalPrep PCR Normalization kit (Thermo

338 Fisher Scientific). One library per PCR plate was prepared by pooling all the amplified and

339 normalized DNA. The concentration of each library was determined using Qubit. For each

340 sequencing run, an equimolar concentration of each library was pooled and purified using Ampure

341 XP (Beckman Coulter by Thermo Fisher Scientific), according to the manufacturer's protocol. We

342 used Qubit and Bioanalyzer DNA analysis kit (Agilent) to verify the final concentration and

343 quality of the purified DNA. According to MiSeq Illumina guidance, the $4 \mathrm{nM}$ DNA was denatured

344 using $\mathrm{NaOH} 0.2 \mathrm{~N}$ and then diluted to a $14 \mathrm{pM}$ library. Then, it was PE (paired-end) sequenced on 
345 Illumina MiSeq (2 x 300bp), using a 600-cycle MiSeq reagent kit v3, at Agriculture and Agri346 Food Canada.

\section{Bioinformatic analyses}

348 We used BBDuk (http://jgi.doe.gov/data-and-tools/bb-tools/) to remove Illumina adapters.

349 We also removed barcodes and primers and then demultiplexed the Illumina reads. Afterwards,

350 we applied DADA2 v1.12.1 [71] to remove low-quality sequences, correct the Illumina-

351 sequencing amplicon errors, merge paired-end sequences, eliminate chimeric sequences, and

352 identify amplicon sequence variants (ASVs). We used default parameter settings for all functions

353 except for the following functions: i) in filterAndTrim function, we removed all the sequences

354 with fewer than 50 nucleotides (minLen $=50$, instead of 20), ii) in dada function, we set the

355 algorithm to perform pseudo-pooling between samples, and iii) in mergePairs, we set a minimum

356 overlap length of 10 (minOverlap $=10$, instead of 12$)$ in order to merge the forward and reverse

357 reads. We finally used the RDP naive Bayesian classifier method implemented in DADA2 with 358 the SILVA 132 rRNA database $[72,73]$ to annotate the taxonomic identity of ASVs.

\section{Sample quality control, decontamination and rarefaction}

360 After verifying the presence and composition of the mock communities in the positive

361 controls, we removed them from the dataset. To minimize sequence artifacts caused by PCR and

362 sequencing errors [74], which may result in spurious ASVs, we performed the following steps of

363 quality filtering and decontamination: (1) removing ASVs that were not taxonomically annotated

364 as belonging to a bacterial phylum ( $0.78 \%$ of all sequences); (2) eliminating the outlier samples

365 (including two of the negative control samples) that had a very different composition from the

366 other samples based on the non-metric multidimensional scaling (NMDS) on Bray-Curtis

367 dissimilarities [75]; (3) filtering all the samples with less than 1,000 sequences (39 samples, 
368 including all the other negative controls, except for the phyllosphere and soil sampling bag 369 controls); (4) removing the contaminating DNA from the bacterial communities using the 370 prevalence method (probability threshold $=0.5$ ) of the decontam package v1.1.2 [76] in R v4.0.0

371 [77], which identified 50 ASVs as contaminants based on the most prevalent ASVs in the negative 372 controls; (5) eliminating all the ASVs recognized as chloroplasts or mitochondria (0.15\%); (6)

373 excluding the samples with low alpha diversity (Shannon richness $<2$, including the soil sampling 374 bag control and one phyllosphere sample); (7) removing the rare ASVs with less than 10 reads 375 (37\% of ASVs); and (8) eliminating again the outlier samples detected in the denoised dataset (five 376 samples, including the last remaining negative control, one phyllosphere and four soil samples), 377 which had a highly different composition (based on NMDS on Bray-Curtis dissimilarities) or 378 species richness (based on Shannon diversity) from the other samples of the same habitat. Finally, 379 we selected cutoffs to rarefy samples based on inspection of rarefaction curves for phyllosphere 380 and soil samples, choosing rarefaction cutoffs that approached saturation in the ASV rarefaction 381 curve while keeping as many samples as possible. We first rarefied the soybean and corn 382 phyllosphere and soil samples to 5,000 reads per sample, which excluded 12 samples that 383 contained insufficient numbers of sequences and 699 ASVs. We then made a subset of non-treated 384 (control) samples (119 samples and 13,042 ASVs) to study the soybean and corn phyllosphere and 385 soil bacterial community diversity and composition. We also made a subset of phyllosphere 386 samples (110 samples and 6,695 ASVs) to study the variations in the phyllosphere bacterial 387 community diversity and composition in response to neonicotinoid seed treatment. Since soil 388 samples had more sequences per sample than phyllosphere samples, we rarefied the dataset again, 389 this time to 10,000 reads per sample, which excluded 22 samples that contained insufficient 390 numbers of sequences and 195 ASVs. Therefore, we subset soil samples to study the effects of 
neonicotinoid seed treatment on their bacterial diversity and composition (132 samples and 13,137

392 ASVs). Overall, quality control and filtering, decontamination, and rarefaction procedures at 5,000

393 and 10,000 cutoffs (Fig. 5) respectively eliminated $41 \%$ and $39 \%$ of the low-quality ASVs and

$39420 \%$ and $23 \%$ of the samples (including all the 15 negative controls). We then analyzed these

395 datasets using different $\mathrm{R}$ packages.

\section{Statistical analyses}

\section{Characterization of phyllosphere and soil bacterial composition and diversity}

398 To identify the bacterial composition and diversity of the soybean and corn phyllosphere

399 and soil, we analyzed the non-neonicotinoid treated (control) samples that were rarefied to 5,000

400 reads per sample. This dataset contained 119 samples (including 30 soybean and 21 corn

401 phyllosphere samples, as well as 45 soybean and 23 corn soil samples) with an average of 1,174 \pm

$40265.0 \mathrm{ASVs}($ mean $\pm \mathrm{SE})$ per sample. We conducted permutational multivariate analyses of variance

403 (PERMANOVA) [78] using the adonis2 function of the vegan package in $\mathrm{R}$ with 999 permutations

404 first on the whole community dissimilarity matrix to test for the effects of habitats (phyllosphere

405 and soil), host species (soybean and corn), time (month and year), and their interactions on the

406 bacterial composition variation (model: . habitat * host species * month/year), and then on each

407 habitat individually to test for the effects of host species, time and their interactions on the bacterial

408 community composition (model: . host species * month/year).

409 To assess the bacterial community homogeneity of each habitat and also each host species

410 individually in phyllosphere and soil, we used a multivariate homogeneity test of groups

411 dispersions using the betadisper function of the vegan package in $\mathrm{R}$ and then performed an analysis

412 of variance (ANOVA)-like permutation test with 999 permutations to evaluate the significance of 413 the results. 
Furthermore, we used the Shannon index to estimate the soybean and corn phyllosphere

415 and soil bacterial alpha diversity. We conducted the non-parametric Wilcoxon rank-sum test [79]

416 to compare the Shannon diversity for the following groups: between phyllosphere versus soil

417 samples, and individually in each habitat between soybean versus corn samples, among years, and

418 among months. This test was applied to determine the statistically significant differences of the

419 bacterial ASVs richness among the mentioned groups. We adjusted the p-values using Holm's 420 method [80].

421 To understand which families drove the variation in bacterial composition across habitats

422 and hosts, we studied the correlations among all the bacterial families of soybean and corn 423 phyllosphere and soil, which had an average relative abundance of more than 0.01 , with their 424 habitats and hosts. To achieve this, we used the envfit function of the vegan package in $\mathrm{R}$, which 425 computes the goodness of fit values (R2) and their significance (with 999 permutations) of the 426 vectors of bacterial families relative abundance onto the principal coordinate analysis (PCoA) 427 ordination (based on Bray-Curtis distances).

428 Effects of neonicotinoid seed treatment on bacterial community composition, diversity and 429 temporal variation

430 To study the bacterial community variations in response to neonicotinoid seed treatment, 431 we separately analyzed the rarefied phyllosphere $(5,000$ reads per sample) and soil (10,000 reads 432 per sample) samples. The phyllosphere dataset contained 110 samples (including 67 soybean and 43343 corn samples) with an average of $391.1 \pm 20.3$ ASVs (mean \pm SE) per sample, and the soil 434 dataset contained 132 samples (including 85 soybean and 47 corn samples) with an average of $4352,257 \pm 30.0 \mathrm{ASVs}($ mean $\pm \mathrm{SE}$ ) per sample. We evaluated the relationships between bacterial 436 communities and their host species, time (year and month) and neonicotinoid seed treatment, using 
437 a PERMANOVA with 999 permutations on the community matrix (model: . host species * year

$438 *$ month * neonicotinoid seed treatment) for each habitat individually. We also performed a PCoA

439 (on Bray-Curtis dissimilarities) per habitat to illustrate the composition variation in the bacterial

440 communities. Given the strong effects of host plants on the phyllosphere [5, 6, 10] and soil [11]

441 bacterial community structure and according to our preliminary results, we also studied the

442 soybean and corn samples individually to understand whether the impacts of neonicotinoid seed

443 treatment on the patterns of bacterial community variation were masked by host species. Thereafter

444 for each crop, we performed a PCoA (based on Bray-Curtis distances) and a PERMANOVA test

445 (model: . year * month * neonicotinoid seed treatment) to explore the phyllosphere and soil

446 bacterial community composition and the drivers of its variation.

447 We used the Shannon index to determine the phyllosphere and soil bacterial alpha

448 diversity. Then, we conducted the non-parametric Wilcoxon rank-sum test to compare the Shannon

449 diversity between the control versus neonicotinoid-treated samples in each habitat, as well as in 450 soybean and corn separately for each habitat (model: Shannon neonicotinoid seed treatment).

451 For each habitat individually, we used a linear model to evaluate the effects of neonicotinoid 452 application on the bacterial alpha diversity across time (phyllosphere model: Shannon 453 neonicotinoid seed treatment * month; soil model: Shannon $\sim$ neonicotinoid seed treatment $*$ 454 month * year), followed by an ANOVA test to determine the significant interactions. We then used 455 the Wilcoxon rank-sum test, in which we grouped the samples by month (phyllosphere and soil 456 models: Shannon $\sim$ neonicotinoid seed treatment, group by $=$ month) and by year (soil model: 457 Shannon $\sim$ neonicotinoid seed treatment, group by $=$ year) to identify the significance of the 458 interactions suggested by our model. We adjusted the p-values using Holm's method. 
To determine the differentially abundant ASVs and taxa between control and

461 neonicotinoid-treated samples in each habitat, we performed a differential expression analysis of

462 sequence data (DESeq2 [81]) using the Wald significance test with a local fit type and compared

463 the results by estimating the $\log 2$ fold changes. We analyzed the non-rarefied and non-normalized

464 quality filtered and decontaminated bacterial phyllosphere (118 samples, including 58 control and

46560 neonicotinoid-treated samples) and soil samples (137 samples, including 69 control and 68

466 neonicotinoid-treated samples) separately to identify the differentially abundant ASVs and taxa

467 using the DESeq2 test. We then adjusted the p-values (significance cutoff of 0.05) using the

468 Benjamini-Hochberg false-discovery rate (FDR) method [82] to identify the significantly

469 differentially abundant ASVs and taxa between the control and neonicotinoid-treated samples

470 during three years of rotation individually for each habitat.

471

472 List of abbreviations

473 ANOVA Analysis of variance

474 ASV Amplicon sequence variant

475 DESeq2 Differential expression analysis of sequence data

476 FDR False-discovery rate

477 NMDS Non-metric multidimensional scaling

478 NST Neonicotinoid seed treatment

479 PCoA Principal coordinate analysis

480 PERMANOVA Permutational analysis of variance 


\section{Declarations}

484 Ethics approval and consent to participate

485 Not applicable

\section{Consent for publication}

487 Not applicable

488 Availability of data and materials

489 We have deposited the raw sequences at the NCBI Sequence Read Archive (SRA): PRJNA662376.

490 Our scripts to perform the analyses of the current study are available in the following GitHub 491 repository: https://github.com/memoll/acadie_16s.

\section{Competing interests}

493 The authors declare no conflict of interest.

\section{Acknowledgements}

495 We are grateful to Michel Fortin, Éléonore Tremblay, Pierre-Yves Véronneau, Katherine Bisaillon 496 and other colleagues in AAFC for assistance in crop cultivation and sample collection, processing 497 and sequencing. We also thank Gaston Mercier (AAFC) for performing soil physicochemical 498 analysis. Finally, we thank Étienne Lord (AAFC) for his help in data processing, and Geneviève 499 Labrie (CRAM) and Annie-Ève Gagnon (AAFC) for their valuable scientific advice and $500 \quad$ suggestions.

\section{$501 \quad$ Funding}

502 This research was funded by Agriculture and Agri-Food Canada (BM), the Natural Sciences and 503 Engineering Research Council of Canada Discovery Grants program (SK) and the Canada 504 Research Chair (SK). It was also enabled in part by support provided by Compute Canada and 
Calcul Quebec.

\section{Author contributions}

507 MP, BM and SK conceived and designed the study; BM and SK obtained the funding; MP

508 collected and analyzed data and wrote the manuscript; All authors critically reviewed and edited

509 the manuscript.

\section{References}

512 1. Vorholt JA. Microbial life in the phyllosphere. Nat Rev Microbiol. 2012;10:828-40.

513 2. Doran JW, Zeiss MR. Soil health and sustainability: managing the biotic component of soil quality.

514 Appl Soil Ecol. 2000;15:3-11.

515 3. Garbeva P, van Veen JA, van Elsas JD. Microbial diversity in soil: selection of microbial populations

516 by plant and soil type and implications for disease suppressiveness. Annu Rev Phytopathol. 2004;42:24351770.

518 4. Whipps JM, Hand P, Pink D, Bending GD. Phyllosphere microbiology with special reference to 519 diversity and plant genotype. J Appl Microbiol. 2008;105:1744-55.

520 5. Knief C, Ramette A, Frances L, Alonso-Blanco C, Vorholt JA. Site and plant species are important 521 determinants of the Methylobacterium community composition in the plant phyllosphere. ISME J. $522 \quad 2010 ; 4: 719-28$.

6. Kembel SW, O’Connor TK, Arnold HK, Hubbell SP, Wright SJ, Green JL. Relationships between phyllosphere bacterial communities and plant functional traits in a neotropical forest. Proc Natl Acad Sci

525 U S A. 2014;111:13715-20.

526 7. Redford AJ, Fierer N. Bacterial succession on the leaf surface: a novel system for studying

527 successional dynamics. Microb Ecol. 2009;58:189-98.

528 8. Sugiyama A, Ueda Y, Zushi T, Takase H, Yazaki K. Changes in the Bacterial Community of Soybean 529 Rhizospheres during Growth in the Field. PLoS ONE. 2014;9:e100709.

530 9. Wagner MR, Lundberg DS, Del Rio TG, Tringe SG, Dangl JL, Mitchell-Olds T. Host genotype and 531 age shape the leaf and root microbiomes of a wild perennial plant. Nat Commun. 2016;7:12151.

532 10. Laforest-Lapointe I, Messier C, Kembel SW. Tree phyllosphere bacterial communities: exploring the magnitude of intra- and inter-individual variation among host species. PeerJ. 2016;4:e2367.

534 11. Wieland G, Neumann R, Backhaus H. Variation of microbial communities in soil, rhizosphere, and 535 rhizoplane in response to crop species, soil type, and crop development. Appl Environ Microbiol.

$536 \quad 2001 ; 67: 5849-54$.

537 12. Clairmont LK, Stevens KJ, Slawson RM. Site-specific differences in microbial community structure 538 and function within the rhizosphere and rhizoplane of wetland plants is plant species dependent. 
Rhizosphere. 2019;9:56-68.

13. Tarlera S, Jangid K, Ivester AH, Whitman WB, Williams MA. Microbial community succession and bacterial diversity in soils during 77,000 years of ecosystem development. FEMS Microbiol Ecol. 2008;64:129-40.

14. Hannula SE, Kielak AM, Steinauer K, Huberty M, Jongen R, De Long JR, et al. Time after Time: Temporal Variation in the Effects of Grass and Forb Species on Soil Bacterial and Fungal Communities. MBio. 2019;10. doi:10.1128/mBio.02635-19.

15. Samaritani E, Mitchell EAD, Rich J, Shrestha J, Fournier B, Frey B. Soil bacterial communities and ecosystem functioning change more strongly with season than habitat in a restored floodplain. Appl Soil Ecol. 2017;112:71-8.

16. Schimel J, Balser TC, Wallenstein M. Microbial stress-response physiology and its implications for ecosystem function. Ecology. 2007;88:1386-94.

17. Itoh H, Navarro R, Takeshita K, Tago K, Hayatsu M, Hori T, et al. Bacterial population succession and adaptation affected by insecticide application and soil spraying history. Front Microbiol. 2014;5:457.

18. Fierer N, Nemergut D, Knight R, Craine JM. Changes through time: integrating microorganisms into the study of succession. Res Microbiol. 2010;161:635-42.

19. Rodríguez-Valdecantos G, Manzano M, Sánchez R, Urbina F, Hengst MB, Lardies MA, et al. Early successional patterns of bacterial communities in soil microcosms reveal changes in bacterial community composition and network architecture, depending on the successional condition. Applied Soil Ecology. 2017;120:44-54.

20. Fox JE, Gulledge J, Engelhaupt E, Burow ME, McLachlan JA. Pesticides reduce symbiotic efficiency of nitrogen-fixing rhizobia and host plants. Proc Natl Acad Sci U S A. 2007;104:10282-7.

21. Lo CC. Effect of pesticides on soil microbial community. J Environ Sci Health B. 2010;45:348-59.

22. Hussain S, Siddique T, Saleem M, Arshad M, Khalid A. Impact of Pesticides on Soil Microbial Diversity, Enzymes, and Biochemical Reactions - Chapter 5. In: Advances in Agronomy. Academic Press; 2009. p. 159-200.

23. Kagabu S. Studies on the Synthesis and Insecticidal Activity of Neonicotinoid Compounds. J Pestic Sci. 1996;21:231-9.

24. Tomizawa M, Casida JE. Neonicotinoid insecticide toxicology: mechanisms of selective action. Annu Rev Pharmacol Toxicol. 2005;45:247-68.

25. Tomizawa M, Latli B, Casida JE. Structure and Function of Insect Nicotinic Acetylcholine Receptors Studied with Nicotinoid Insecticide Affinity Probes. In: Yamamoto I, Casida JE, editors. Nicotinoid Insecticides and the Nicotinic Acetylcholine Receptor. Tokyo: Springer Japan; 1999. p. 271-92.

26. Tomizawa M, Casida JE. Selective toxicity of neonicotinoids attributable to specificity of insect and mammalian nicotinic receptors. Annu Rev Entomol. 2003;48:339-64.

27. Elbert A, Haas M, Springer B, Thielert W, Nauen R. Applied aspects of neonicotinoid uses in crop protection. Pest Manag Sci. 2008;64:1099-105. 
28. Samson-Robert O, Labrie G, Chagnon M, Fournier V. Neonicotinoid-contaminated puddles of water represent a risk of intoxication for honey bees. PLoS One. 2014;9:e108443.

29. Douglas MR, Tooker JF. Large-scale deployment of seed treatments has driven rapid increase in use of neonicotinoid insecticides and preemptive pest management in US field crops. Environ Sci Technol. 2015;49:5088-97.

30. Bonmatin J-M, Giorio C, Girolami V, Goulson D, Kreutzweiser DP, Krupke C, et al. Environmental fate and exposure; neonicotinoids and fipronil. Environ Sci Pollut Res Int. 2015;22:35-67.

31. Sur R, Stork A. Uptake, translocation and metabolism of imidacloprid in plants. Bull Insectology. 2003;56:35-40.

32. Bonmatin JM, Marchand PA, Charvet R, Moineau I, Bengsch ER, Colin ME. Quantification of Imidacloprid Uptake in Maize Crops. Journal of Agricultural and Food Chemistry. 2005;53:5336-41.

33. Girolami V, Mazzon L, Squartini A, Mori N, Marzaro M, Di Bernardo A, et al. Translocation of neonicotinoid insecticides from coated seeds to seedling guttation drops: a novel way of intoxication for bees. J Econ Entomol. 2009;102:1808-15.

34. Myers C, Hill E. Benefits of neonicotinoid seed treatments to soybean production. Epa J. 2014.

35. Alford A, Krupke CH. Correction: Translocation of the neonicotinoid seed treatment clothianidin in maize. PLoS One. 2017;12:e0186527.

36. Zhang P, Zhang X, Zhao Y, Wei Y, Mu W, Liu F. Effects of imidacloprid and clothianidin seed treatments on wheat aphids and their natural enemies on winter wheat. Pest Manag Sci. 2016;72:1141-9.

37. Goulson D. REVIEW: An overview of the environmental risks posed by neonicotinoid insecticides. Journal of Applied Ecology. 2013;50:977-87.

38. Labrie G, Gagnon A-È, Vanasse A, Latraverse A, Tremblay G. Impacts of neonicotinoid seed treatments on soil-dwelling pest populations and agronomic parameters in corn and soybean in Quebec (Canada). PLoS One. 2020;15:e0229136.

39. Pisa LW, Amaral-Rogers V, Belzunces LP, Bonmatin JM, Downs CA, Goulson D, et al. Effects of neonicotinoids and fipronil on non-target invertebrates. Environ Sci Pollut Res Int. 2015;22:68-102.

40. Iwasa T, Motoyama N, Ambrose JT, Roe RM. Mechanism for the differential toxicity of neonicotinoid insecticides in the honey bee, Apis mellifera. Crop Prot. 2004;23:371-8.

41. Sanchez-Bayo F, Goka K. Pesticide residues and bees--a risk assessment. PLoS One. 2014;9:e94482.

42. Samson-Robert O, Labrie G, Chagnon M, Fournier V. Planting of neonicotinoid-coated corn raises honey bee mortality and sets back colony development. PeerJ. 2017;5:e3670.

43. Moulas C, Petsoulas C, Rousidou K, Perruchon C, Karas P, Karpouzas DG. Effects of systemic pesticides imidacloprid and metalaxyl on the phyllosphere of pepper plants. Biomed Res Int. 2013;2013:969750.

44. Zhang B, Zhang H, Jin B, Tang L, Yang J, Li B, et al. Effect of cypermethrin insecticide on the microbial community in cucumber phyllosphere. J Environ Sci . 2008;20:1356-62. 
45. Zhang B, Bai Z, Hoefel D, Tang L, Wang X, Li B, et al. The impacts of cypermethrin pesticide application on the non-target microbial community of the pepper plant phyllosphere. Sci Total Environ. 2009;407:1915-22.

46. Cycoń M, Markowicz A, Borymski S, Wójcik M, Piotrowska-Seget Z. Imidacloprid induces changes in the structure, genetic diversity and catabolic activity of soil microbial communities. J Environ Manage. $617 \quad 2013 ; 131: 55-65$. 47. Yu B, Chen Z, Lu X, Huang Y, Zhou Y, Zhang Q, et al. Effects on soil microbial community after exposure to neonicotinoid insecticides thiamethoxam and dinotefuran. Sci Total Environ.

$620 \quad 2020 ; 725: 138328$.

621 48. Singh J, Singh DK. Ammonium, Nitrate and Nitrite Nitrogen and Nitrate Reductase Enzyme Activity 622 in Groundnut (Arachis hypogaea L.) Fields After Diazinon, Imidacloprid and Lindane Treatments.

623 Journal of Environmental Science and Health, Part B. 2006;41:1305-18.

624 49. Ahemad M, Khan MS. Ecological Assessment of Biotoxicity of Pesticides towards Plant Growth 625 Promoting Activities of Pea (Pisum sativum)-Specific Rhizobium sp. Strain MRP1. Journal of the Science 626 of Food and Agriculture. 2012;24:334-43.

627 50. Filimon MN, Voia SO, Popescu R, Dumitrescu G, Ciochina LP, Mituletu M, et al. The effect of some 628 insecticides on soil microorganisms based on enzymatic and bacteriological analyses. Rom Biotechnol 629 Lett. 2015;20:10439-47.

630 51. Cycoń M, Piotrowska-Seget Z. Biochemical and microbial soil functioning after application of the insecticide imidacloprid. J Environ Sci . 2015;27:147-58. Imidacloprid-Degrading Mycobacterium sp. Strain MK6 from an Egyptian Soil. J Agric Food Chem. 2015;63:4721-7.

53. Guo L, Fang W-W, Guo L-L, Yao C-F, Zhao Y-X, Ge F, et al. Biodegradation of the neonicotinoid insecticide acetamiprid by Actinomycetes Streptomyces canus CGMCC 13662 and characterization of the novel nitrile hydratase involved. J Agric Food Chem. 2019;67:5922-31.

54. Tam AC, Behki RM, Khan SU. Isolation and characterization of an s-ethyl-N, Ndipropylthiocarbamate-degrading Arthrobacter strain and evidence for plasmid-associated s-ethyl-N, Ndipropylthiocarbamate degradation. Appl Environ Microbiol. 1987;53:1088-93.

641 55. Laforest-Lapointe I, Messier C, Kembel SW. Host species identity, site and time drive temperate tree 642 phyllosphere bacterial community structure. Microbiome. 2016;4:27.

643 56. Manching HC, Carlson K, Kosowsky S, Smitherman CT, Stapleton AE. Maize Phyllosphere 644 Microbial Community Niche Development Across Stages of Host Leaf Growth. F1000Res. 2017;6:1698. 2016;23:5134-42.

648 58. Zhang P, Ren C, Sun H, Min L. Sorption, desorption and degradation of neonicotinoids in four 649 agricultural soils and their effects on soil microorganisms. Sci Total Environ. 2018;615:59-69. 
post 2013. Environmental Science and Pollution Research. 2017;24:17285-325.

60. Banerjee K, Patil SH, Dasgupta S, Oulkar DP, Adsule PG. Sorption of thiamethoxam in three Indian soils. J Environ Sci Health B. 2008;43:151-6.

654 61. Kurwadkar ST, Dewinne D, Wheat R, McGahan DG, Mitchell FL. Time dependent sorption behavior 655 of dinotefuran, imidacloprid and thiamethoxam. J Environ Sci Health B. 2013;48:237-42.

656 62. Guo L, Dai Z, Guo J, Yang W, Ge F, Dai Y. Oligotrophic bacterium Hymenobacter latericoloratus 657 CGMCC 16346 degrades the neonicotinoid imidacloprid in surface water. AMB Express. 2020;10:7.

658 63. Pandey G, Dorrian SJ, Russell RJ, Oakeshott JG. Biotransformation of the neonicotinoid insecticides imidacloprid and thiamethoxam by Pseudomonas sp. 1G. Biochem Biophys Res Commun.

$660 \quad 2009 ; 380: 710-4$.

661 64. Podile AR, Krishna Kishore G. Plant growth-promoting rhizobacteria. Plant-Associated Bacteria 662 Springer, Netherlands. 2006;:195-230.

663 65. Kumar A, Bahadur I, Maurya BR, Raghuwanshi R, Meena VS, Singh DK, et al. Does a plant growth664 promoting rhizobacteria enhance agricultural sustainability. J Pure Appl Microbiol. 2015;9:715-24.

66. Pitombo LM, do Carmo JB, de Hollander M, Rossetto R, López MV, Cantarella H, et al. Exploring crop. GCB Bioenergy. 2016;8:867-79.

668 67. Gagic V, Kleijn D, Báldi A, Boros G, Jørgensen HB, Elek Z, et al. Combined effects of agrochemicals 669 and ecosystem services on crop yield across Europe. Ecol Lett. 2017;20:1427-36.

670 68. Kim M-S, Bae J-W, Park E-J. Geographic and Host-Associated Variations in Bacterial Communities 671 on the Floret Surfaces of Field-Grown Broccoli. Appl Environ Microbiol. 2018;84.

672 doi:10.1128/AEM.02837-17.

673 69. Chelius MK, Triplett EW. The Diversity of Archaea and Bacteria in Association with the Roots of 674 Zea mays L. Microb Ecol. 2001;41.

675 70. Redford AJ, Bowers RM, Knight R, Linhart Y, Fierer N. The ecology of the phyllosphere: geographic and phylogenetic variability in the distribution of bacteria on tree leaves. Environmental Microbiology. 2010;12:2885-93.

71. Callahan BJ, McMurdie PJ, Rosen MJ, Han AW, Johnson AJA, Holmes SP. DADA2: High-resolution sample inference from Illumina amplicon data. Nat Methods. 2016;13:581-3.

680 72. Quast C, Pruesse E, Yilmaz P, Gerken J, Schweer T, Yarza P, et al. The SILVA ribosomal RNA gene 681 database project: improved data processing and web-based tools. Nucleic Acids Res. 2013;41 Database 682 issue:D590-6.

683 73. Yilmaz P, Parfrey LW, Yarza P, Gerken J, Pruesse E, Quast C, et al. The SILVA and "All-species 684 Living Tree Project (LTP)” taxonomic frameworks. Nucleic Acids Res. 2014;42:D643-8.

685 74. Acinas SG, Sarma-Rupavtarm R, Klepac-Ceraj V, Polz MF. PCR-induced sequence artifacts and bias: 686 insights from comparison of two 16S rRNA clone libraries constructed from the same sample. Appl

687 Environ Microbiol. 2005;71:8966-9. 
75. Bray JR, Curtis JT. An Ordination of the Upland Forest Communities of Southern Wisconsin. Ecol Monogr. 1957;27:325-49.

76. Davis NM, Proctor DM, Holmes SP, Relman DA, Callahan BJ. Simple statistical identification and removal of contaminant sequences in marker-gene and metagenomics data. Microbiome. 2018;6. doi:10.1186/s40168-018-0605-2.

77. R Core Team. R: A language and environment for statistical computing. R Foundation for Statistical Computing, Vienna, Austria. 2019.

78. Anderson MJ. A new method for non-parametric multivariate analysis of variance. Austral Ecol. 2001;26:32-46.

79. Wilcoxon F. Individual Comparisons by Ranking Methods. Biometrics Bulletin. 1945;1:80.

80. Holm S. A Simple Sequentially Rejective Multiple Test Procedure. Scand Stat Theory Appl. 1979;6:65-70.

81. Love MI, Huber W, Anders S. Moderated estimation of fold change and dispersion for RNA-seq data with DESeq2. Genome Biol. 2014;15:550.

82. Hochberg Y, Benjamini Y. More powerful procedures for multiple significance testing. Stat Med. 1990;9:811-8.

\section{Figures}

Fig. 1 Soybean and corn phyllosphere and soil bacterial community diversity and the families who are driving this diversity pattern. Principal coordinate analysis (PCoA) on Bray-Curtis dissimilarities (A) of the bacterial community composition and the correlations between bacterial family abundances and different axes of the PCoA ordination (B) in the phyllosphere and soil bacterial communities in a three-year soybean/corn rotation in L'Acadie, Quebec, Canada. Ordinations show that habitat (red points: soil, green points: phyllosphere) and host species (circle points: corn, triangle points: soybean) explain the bacterial community composition variations. The axes of the ordinations explain $46.6 \%$ of the variation in the bacterial community composition. Ellipses (A) are shaded based on host species (yellow for corn and green for soybean samples) and represent a 99\% confidence level. Grey arrows (B) indicate the significant correlations ( $\mathrm{P}=0.001$, except for the Pseudomonadaceae family) among the bacterial families that had an average relative abundance of more than 0.01 and their habitat and host species. Arrows directions show the correlations among habitats and host species and arrow length indicates the strength of these correlations. 
Fig. 2 Phyllosphere and soil bacterial community composition variations in response to neonicotinoid seed treatment. Principal coordinate analysis (PCoA) on Bray-Curtis

723 dissimilarities demonstrates the composition of phyllosphere (A and B) and soil (C) bacterial 724 community in a three-year soybean (2016: circles and 2018: cubes) and corn (2017: triangles) 725 rotation in L'Acadie, Quebec, Canada. The phyllosphere bacterial community variation among 726 control (blue points) and neonicotinoid-treated (pink points) samples is masked by the effects of 727 host species (A) and time (B). While in soil (C), the bacterial communities vary among control 728 (green points) and neonicotinoid-treated (red points) samples. Ellipses are shaded based on 729 treatment (blue for control and yellow for neonicotinoid-treated samples) and represent a 95\% 730 confidence level.

Fig. 3 Soybean and corn phyllosphere bacterial community composition variations in response to neonicotinoid seed treatment and year. Principal coordinate analysis (PCoA) on Bray-Curtis dissimilarities illustrates the phyllosphere bacterial variation individually for each host species and year of rotation in L'Acadie, Quebec, Canada: A) soybean (left: year 2016; right: year 2018) and B) corn (year 2017). The shapes of the points represent the month and the colors show the treatment. Ellipses are shaded based on treatment (blue for control and pink for neonicotinoidtreated samples) and represent a 95\% confidence level.

Fig. 4 Phyllosphere and soil bacterial taxa (phyla and genera) associated with control and neonicotinoid seed treatment. Differential expression analysis of sequence data (DESeq2)

742 illustrates the bacterial ASVs that are significantly differentially abundant (adjusted $\mathrm{P}<0.05$ )

743 between control and neonicotinoid-treated samples of soybean and corn phyllosphere (A) and soil

744 (B) in a three-year rotation in L'Acadie. Each point represents one ASV related to a genus on the $745 \mathrm{x}$-axis, and its color shows the phylum it belongs to. The ASVs on the top of each graph 746 ( $\log 2$ FoldChange $>0)$ are associated with the neonicotinoid-treated samples, while the others 747 (log2FoldChange < 0) are related to the controls.

749 Fig. 5 Rarefaction curves of the phyllosphere and soil bacterial ASVs. Rarefaction curves are 750 shown for all the phyllosphere and soil samples according to the observed ASVs richness. Each 751 line and color represent one sample. The sequencing coverage (x-axis: number of sequences) is 
755 Tables

756 Table 1. Main drivers of the phyllosphere and soil bacterial community composition 757 variation in a three-year soybean/corn rotation. PERMANOVA (Bray-Curtis dissimilarities) 758 determines the contributions of habitat and host plant species and their interactions in the soybean 759 and corn phyllosphere and soil bacterial composition variation in a three-year soybean/corn 760 rotation in L'Acadie, Quebec, Canada. (:) represents the interaction between variables. 761 Significance levels for each variable are given by: *** $\mathrm{P}<0.001$; ** $\mathrm{P}<0.01$; $* \mathrm{P}<0.05$; NS, $\mathrm{P}$ $762 \geq 0.05$.

\begin{tabular}{|c|c|c|c|c|c|c|c|c|c|}
\hline \multirow[b]{2}{*}{ Variables } & \multicolumn{3}{|c|}{ Phyllosphere \& Soil } & \multicolumn{3}{|c|}{ Phyllosphere } & \multicolumn{3}{|c|}{ Soil } \\
\hline & $\mathbf{R 2}(\%)$ & $\mathbf{F}$ & $\operatorname{Pr}(>\mathbf{F})$ & $\mathbf{R 2}(\%)$ & $\mathbf{F}$ & $\operatorname{Pr}(>\mathbf{F})$ & $\mathbf{R 2}(\%)$ & $\mathbf{F}$ & $\operatorname{Pr}(>\mathbf{F})$ \\
\hline Habitat & 37.3 & 100.98 & $0.001 * * *$ & - & - & - & - & - & - \\
\hline Month/Year & 2.9 & 3.93 & $0.001 * * *$ & 15.7 & 8.28 & $0.001 * * *$ & 4.6 & 1.66 & $0.002 * *$ \\
\hline Habitat: Host species & 3.7 & 10.07 & $0.001 * * *$ & - & - & - & - & - & - \\
\hline Host species: Month/Year & 2.1 & 2.89 & $0.005 * *$ & 11.4 & 6.02 & $0.001 * * *$ & NS & NS & NS \\
\hline Host species: Month: Year & 2.5 & 2.97 & $0.005 * *$ & 14.6 & 5.14 & $0.001 * * *$ & 8 & 1.94 & $0.001 * * *$ \\
\hline Habitat: Host species: Month & 2.5 & 3.35 & $0.003 * *$ & - & - & - & - & - & - \\
\hline $\begin{array}{l}\text { Habitat: Host species: Month: } \\
\text { Year }\end{array}$ & 7.2 & 3.26 & $0.001 * * *$ & - & - & - & - & - & - \\
\hline
\end{tabular}
Table 2 Bacterial alpha diversity explained by time (year and month) and neonicotinoid seed treatment. Variance in the bacterial alpha diversity (Shannon index) explained by year, month, neonicotinoid seed treatment (NST) in soybean and corn together and individually, interactions

768 between NST and month, and interactions between NST and year. Means and standard errors (SE)

769 of each group are calculated and compared. The significance of their differences is determined 770 using a non-parametric Wilcoxon rank-sum test, and the p-values are adjusted using Holm's 771 method. Significance levels for each variable are given by: **** $\mathrm{P}<0.0001 ; * * * \mathrm{P}<0.001 ; * * \mathrm{P}$ $772<0.01 ; * \mathrm{P}<0.05 ; \mathrm{NS}: \mathrm{P} \geq 0.05$. 


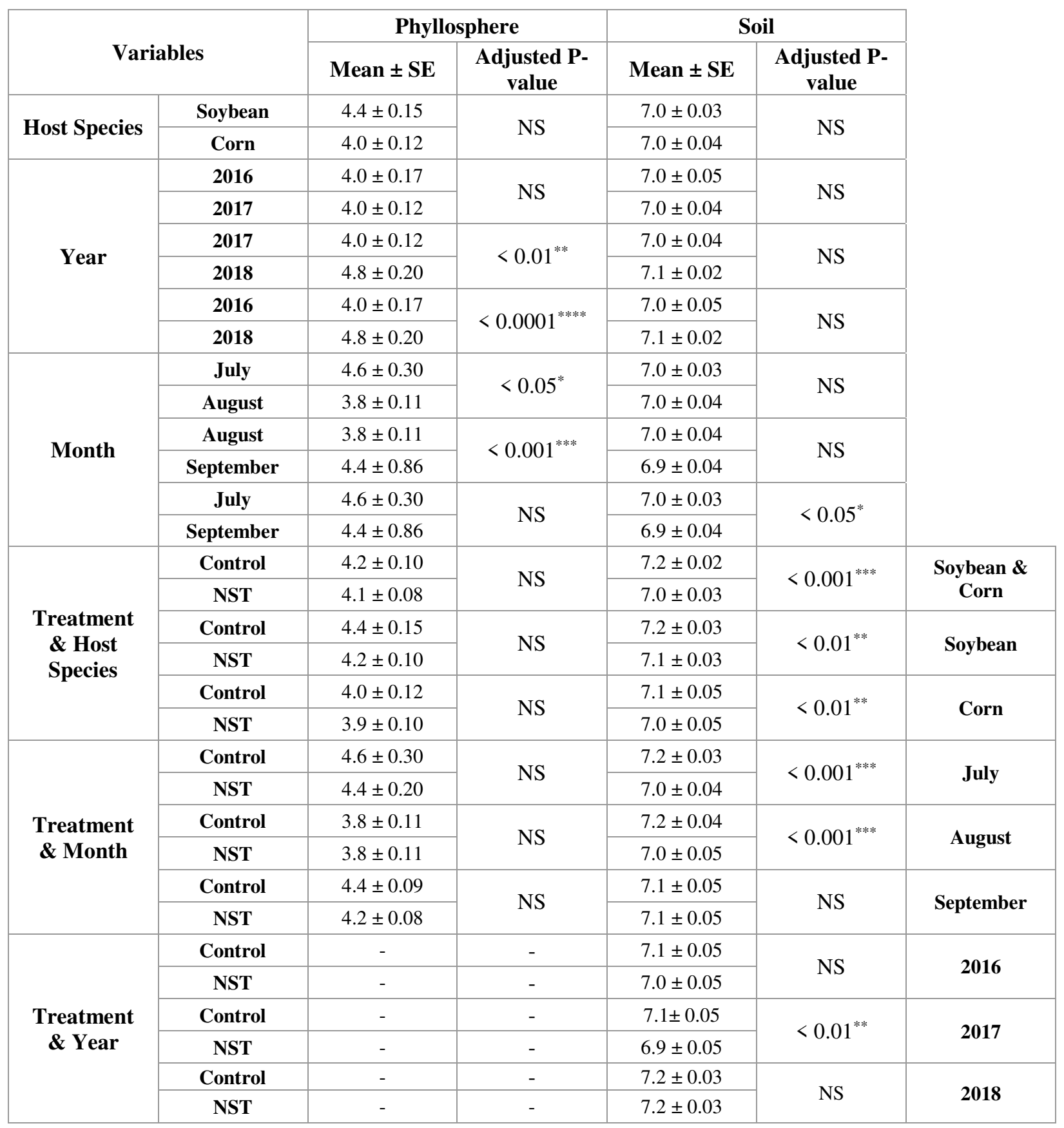


776 Table 3 Drivers of the phyllosphere and soil bacterial community composition variation in 777 response to neonicotinoid seed treatment in a three-year soybean/corn rotation.

778 PERMANOVA (Bray-Curtis dissimilarities) identifies the proportion of bacterial community 779 composition variation explained by host plant species, time (year and month), neonicotinoid seed 780 treatment (NST) and their interactions in the soybean and corn phyllosphere and soil in response 781 to neonicotinoid seed treatment in a three-year soybean/corn rotation in L'Acadie, Quebec, 782 Canada. (:) represents the interaction between variables. Significance levels for each variable are 783 given by: *** $\mathrm{P}<0.001$; ** $\mathrm{P}<0.01 ; * \mathrm{P}<0.05 ; \mathrm{NS}, \mathrm{P} \geq 0.05$.

\begin{tabular}{|c|c|c|c|c|c|c|c|c|c|c|c|c|c|}
\hline \multirow{4}{*}{$\begin{array}{c}\text { Variables } \\
\text { Host } \\
\text { species }\end{array}$} & \multirow{4}{*}{$\begin{array}{c}\begin{array}{c}\text { Bray-Curtis } \\
\text { Dissimilarities }\end{array} \\
\text { R2 }(\%) \\
\text { F } \mid \operatorname{Pr}(>\mathrm{F})\end{array}$} & \multicolumn{6}{|c|}{ Phyllosphere } & \multicolumn{6}{|c|}{ Soil } \\
\hline & & \multicolumn{2}{|c|}{$\begin{array}{c}\text { Soybean \& } \\
\text { Corn }\end{array}$} & \multicolumn{2}{|c|}{ Soybean } & \multicolumn{2}{|c|}{ Corn } & \multicolumn{2}{|c|}{$\begin{array}{c}\text { Soybean \& } \\
\text { Corn }\end{array}$} & \multicolumn{2}{|c|}{ Soybean } & \multicolumn{2}{|c|}{ Corn } \\
\hline & & \multicolumn{2}{|c|}{14.7} & \multicolumn{2}{|c|}{-} & \multicolumn{2}{|c|}{-} & \multicolumn{2}{|c|}{2.4} & \multicolumn{2}{|c|}{-} & \multicolumn{2}{|c|}{-} \\
\hline & & 32.9 & $\begin{array}{c}0.001^{* *} \\
*\end{array}$ & - & - & - & - & 3.61 & $\begin{array}{c}0.001^{* *} \\
*\end{array}$ & - & - & - & - \\
\hline \multirow[b]{2}{*}{ Year } & R2 (\%) & \multicolumn{2}{|c|}{7.4} & \multicolumn{2}{|c|}{13.1} & \multicolumn{2}{|c|}{-} & \multicolumn{2}{|c|}{5.7} & \multicolumn{2}{|c|}{9.2} & \multicolumn{2}{|c|}{-} \\
\hline & $\mathrm{F} \mid \operatorname{Pr}(>\mathrm{F})$ & 16.6 & $\begin{array}{c}0.001^{* *} \\
*\end{array}$ & 16.8 & $\begin{array}{c}0.001^{* *} \\
*\end{array}$ & - & - & 8.42 & $\begin{array}{c}0.001^{* *} \\
*\end{array}$ & 8.92 & $\begin{array}{c}0.001^{\text {** }} \\
*\end{array}$ & - & - \\
\hline \multirow[b]{2}{*}{ Month } & R2 (\%) & \multicolumn{2}{|c|}{15.2} & \multicolumn{2}{|c|}{28.3} & \multicolumn{2}{|c|}{30} & \multicolumn{2}{|c|}{2.6} & \multicolumn{2}{|c|}{3.2} & \multicolumn{2}{|c|}{5.8} \\
\hline & $\mathrm{F} \mid \operatorname{Pr}(>\mathrm{F})$ & $\begin{array}{c}16.9 \\
6\end{array}$ & $\begin{array}{c}0.001^{* *} \\
*\end{array}$ & $\begin{array}{c}18.2 \\
7\end{array}$ & $\begin{array}{c}0.001^{* *} \\
*\end{array}$ & 9.25 & $\begin{array}{c}0.001^{* *} \\
*\end{array}$ & 1.89 & $\begin{array}{c}0.001^{* * *} \\
*\end{array}$ & 1.55 & $0.012^{*}$ & 1.39 & $0.036^{*}$ \\
\hline \multirow[b]{2}{*}{ NST } & R2 (\%) & \multicolumn{2}{|c|}{1.3} & & .6 & & 3 & & 6 & & 4 & & 7 \\
\hline & $\mathrm{F} \mid \operatorname{Pr}(>\mathrm{F})$ & 2.81 & $0.002^{* *}$ & 2.12 & $0.021^{*}$ & 3.3 & $\begin{array}{c}0.001^{* *} \\
*\end{array}$ & 3.82 & $\begin{array}{c}0.001^{* *} \\
*\end{array}$ & 3.33 & $\begin{array}{c}0.001^{\text {** }} \\
*\end{array}$ & 1.78 & $0.017^{*}$ \\
\hline NST: & R2 (\%) & & .2 & & - & & - & & $S$ & & - & & . \\
\hline $\begin{array}{c}\text { Host } \\
\text { species }\end{array}$ & $\mathrm{F} \mid \operatorname{Pr}(>\mathrm{F})$ & 2.56 & $0.002^{* *}$ & - & - & - & - & NS & NS & - & - & - & - \\
\hline NST: & R2 (\%) & & .8 & & IS & & - & & 1 & & 8 & & . \\
\hline Year & $\mathrm{F} \mid \operatorname{Pr}(>\mathrm{F})$ & 1.73 & $0.043^{*}$ & NS & NS & - & - & 1.63 & $0.030^{*}$ & 1.73 & $0.014^{*}$ & - & - \\
\hline NST: & R2 (\%) & & IS & & IS & & JS & & 4 & & S & & 6 \\
\hline Month & $\mathrm{F} \mid \operatorname{Pr}(>\mathrm{F})$ & NS & NS & NS & NS & NS & NS & 1.8 & $0.002^{* *}$ & NS & NS & 1.34 & $0.048^{*}$ \\
\hline NST: & R2 (\%) & & .4 & & - & & - & & $S$ & & 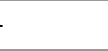 & & . \\
\hline $\begin{array}{c}\text { Host } \\
\text { species }\end{array}$ & $\mathrm{F} \mid \operatorname{Pr}(>\mathrm{F})$ & 1.55 & $0.028^{*}$ & - & - & - & - & NS & NS & - & - & - & - \\
\hline NST: & R2 (\%) & & .4 & & JS & & - & & $S$ & & $S$ & & . \\
\hline Month & $\mathrm{F} \mid \operatorname{Pr}(>\mathrm{F})$ & 1.57 & $0.026^{*}$ & NS & NS & - & - & NS & NS & NS & NS & - & - \\
\hline
\end{tabular}


Table 4 Phyllosphere and soil bacterial phyla associated with control and neonicotinoid seed treatment. Differential expression analysis of sequence data (DESeq2) identified the bacterial phyla of the ASVs that are significantly differentially abundant (adjusted $\mathrm{P}<0.05$ ) between control and neonicotinoid-treated samples of soybean and corn phyllosphere and soil in a three-year rotation in L'Acadie.

\begin{tabular}{|c|c|c|c|}
\hline \multirow{2}{*}{ Habitat } & \multirow{2}{*}{ Phylum } & \multicolumn{2}{|c|}{ Number of ASVs associated with treatment } \\
\hline & & Control & Neonicotinoid-treated \\
\hline \multirow{4}{*}{ Phyllosphere } & Actinobacteria & 1 & 3 \\
\hline & Bacteroidetes & 0 & 14 \\
\hline & Deinococcus-Thermus & 1 & 0 \\
\hline & Proteobacteria & 10 & 5 \\
\hline \multirow{11}{*}{ Soil } & Acidobacteria & 11 & 0 \\
\hline & Actinobacteria & 27 & 31 \\
\hline & Bacteroidetes & 11 & 1 \\
\hline & Chloroflexi & 3 & 33 \\
\hline & Firmicutes & 2 & 0 \\
\hline & Gemmatimonadetes & 27 & 2 \\
\hline & Nitrospirae & 2 & 0 \\
\hline & Patescibacteria & 0 & 1 \\
\hline & Proteobacteria & 139 & 0 \\
\hline & Spirochaetes & 1 & 0 \\
\hline & Verrucomicrobia & 3 & 0 \\
\hline
\end{tabular}

\section{Supplementary information}

\section{Additional file}

793 Supplementary Tables. This additional file contains 3 supplementary tables, referred to in the main 794 text. 
Figures

A)

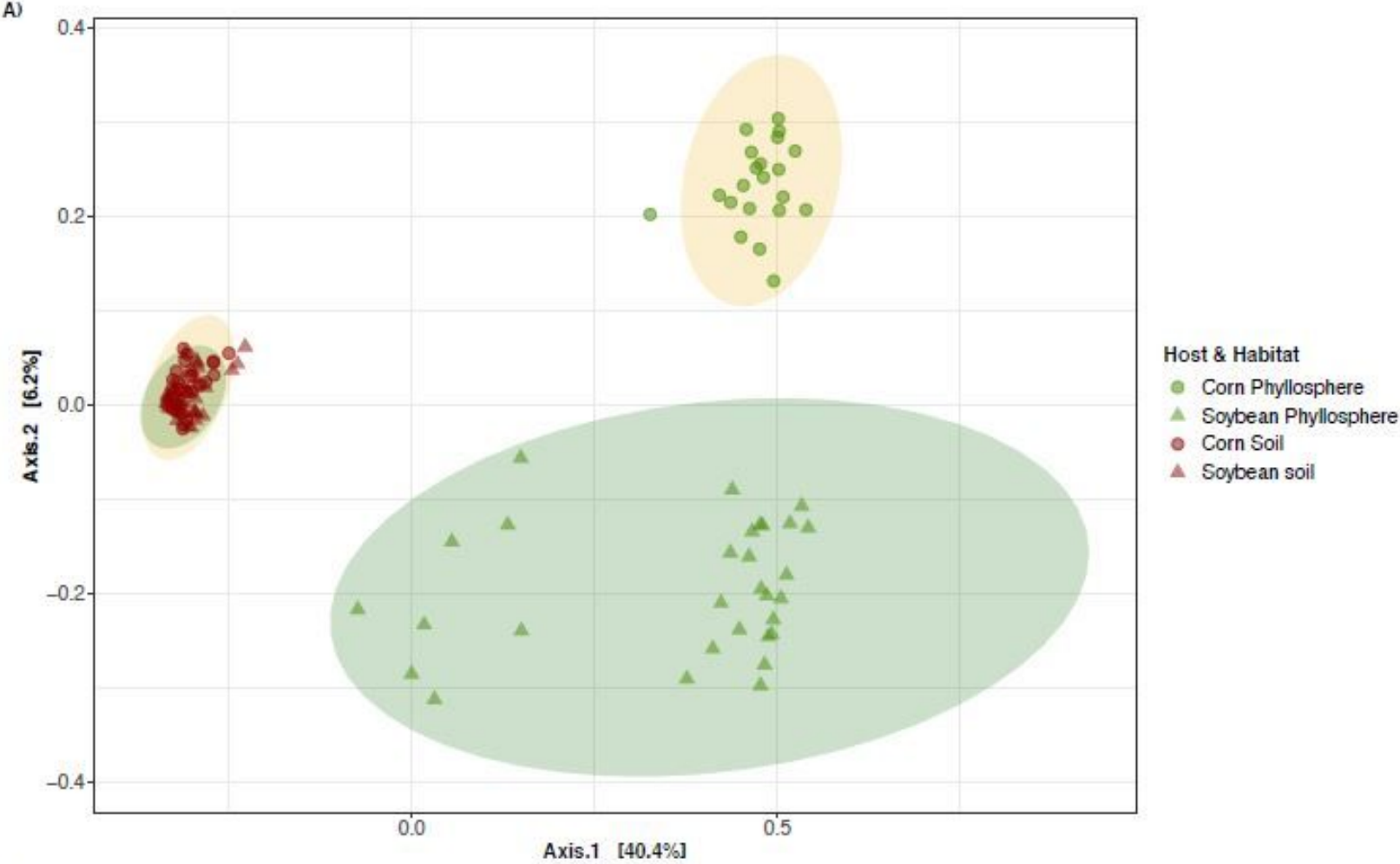

B)

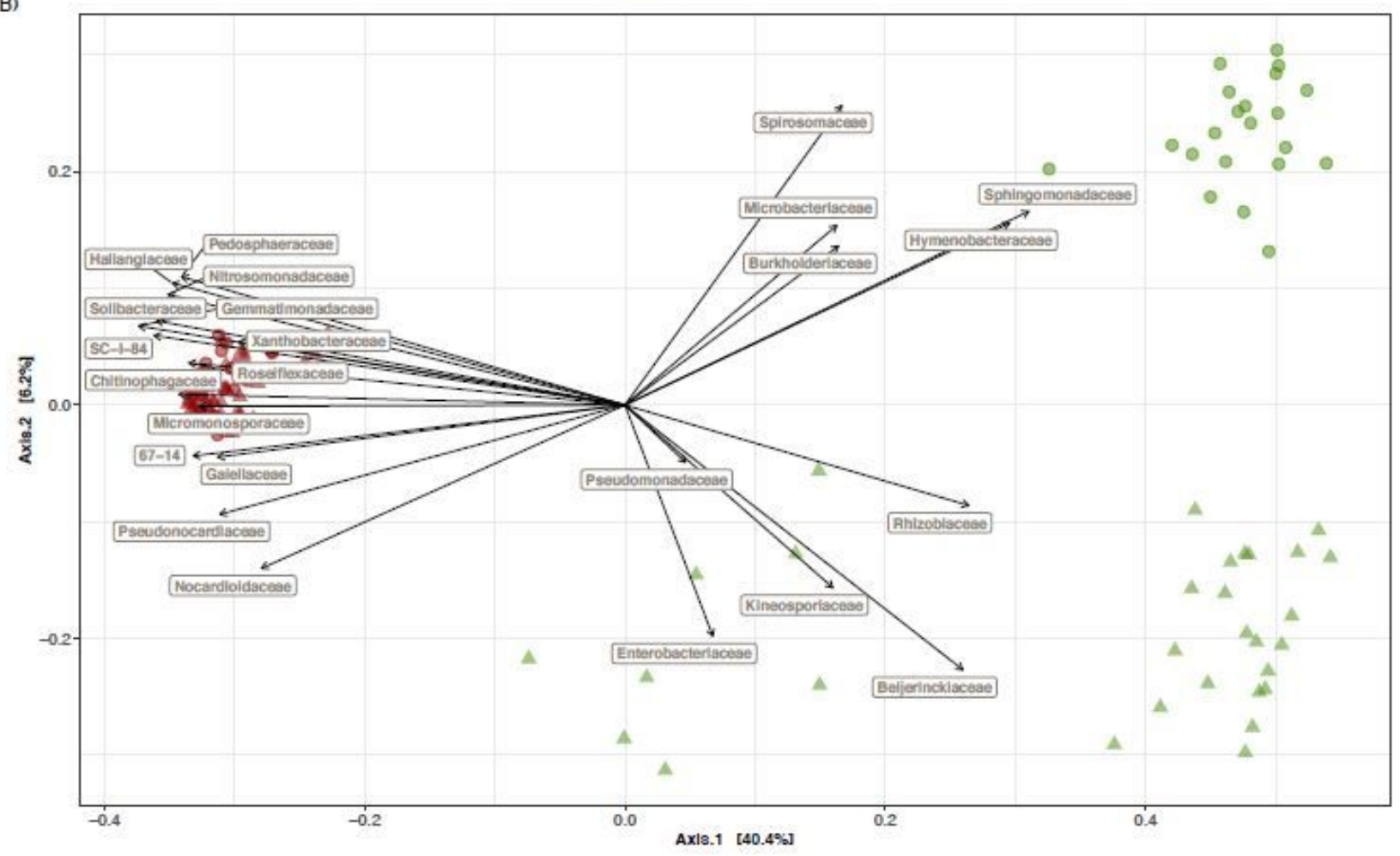

Figure 1

Soybean and corn phyllosphere and soil bacterial community diversity and the families who are driving this diversity pattern. Principal coordinate analysis (PCoA) on Bray-Curtis dissimilarities ( $A)$ of the bacterial community composition and the correlations between bacterial family abundances and 
different axes of the PCoA ordination (B) in the phyllosphere and soil bacterial communities in a threeyear soybean/corn rotation in L'Acadie, Quebec, Canada. Ordinations show that habitat (red points: soil, green points: phyllosphere) and host species (circle points: corn, triangle points: soybean) explain the bacterial community composition variations. The axes of the ordinations explain $46.6 \%$ of the variation in the bacterial community composition. Ellipses $(A)$ are shaded based on host species (yellow for corn and green for soybean samples) and represent a $99 \%$ confidence level. Grey arrows (B) indicate the significant correlations ( $P=0.001$, except for the Pseudomonadaceae family) among the bacterial families that had an average relative abundance of more than 0.01 and their habitat and host species. Arrows directions show the correlations among habitats and host species and arrow length indicates the strength of these correlations. 
A)

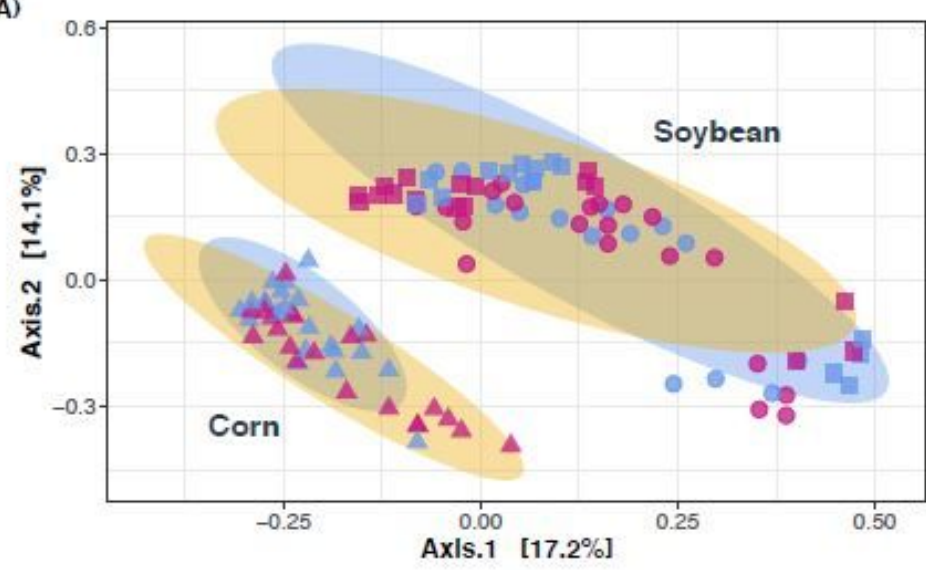

Phyllosphere: Treatment, Host \& Year

Control Soybean 2016

Neonicotinoid-treated Soybean 2016

Control Corn 2017

Neonicotinoid-treated Corn 2017

Control Soybean 2018

Neonicotinoid-treated Soybean 2018

Treatment ellipses

Control

Neonicotinoid-treated

B)

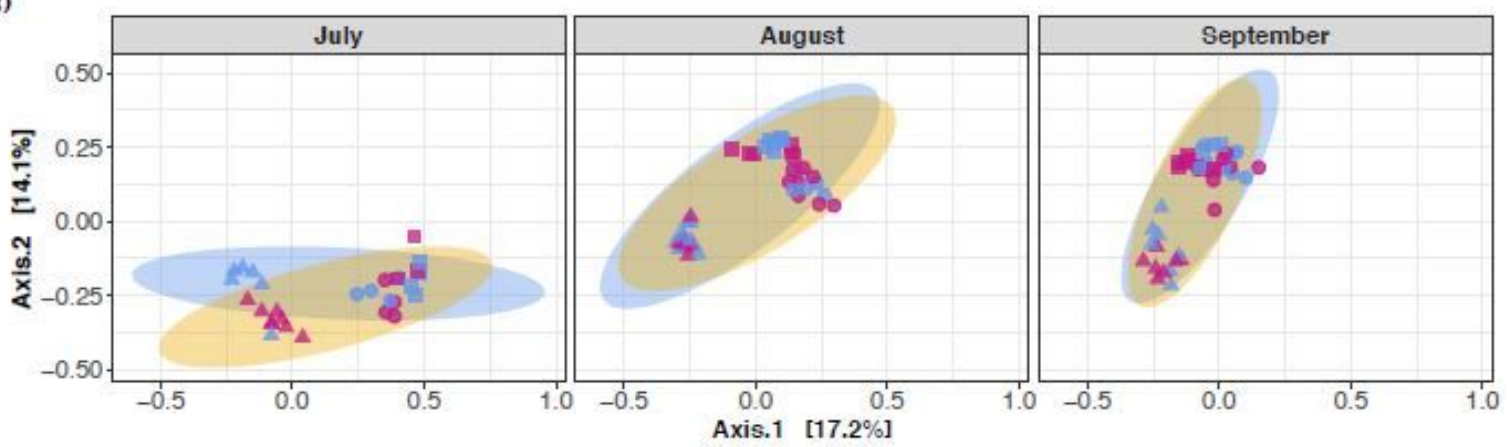

C)

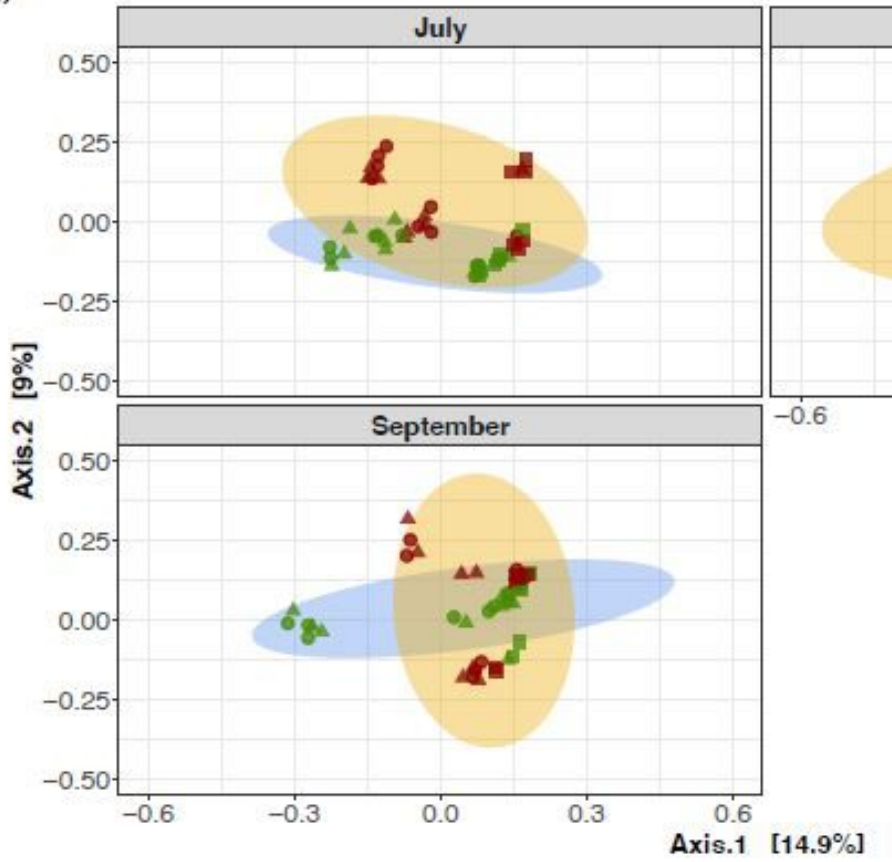

August

Soll: Treatment, Host \& Year

- Control Soybean 2016

- Neonicotinoid-treated Soybean 2016

A Control Corn 2017

A Neonicotinoid-treated Corn 2017

II Control Soybean 2018

Neonicotinoid-treated Soybean 2018

Treatement ellipses

Control

Neonicotinoid-treated

\section{Figure 2}

Phyllosphere and soil bacterial community composition variations in response to neonicotinoid seed treatment. Principal coordinate analysis (PCoA) on Bray-Curtis dissimilarities demonstrates the composition of phyllosphere (A and B) and soil (C) bacterial community in a three-year soybean (2016: circles and 2018: cubes) and corn (2017: triangles) rotation in L'Acadie, Quebec, Canada. The phyllosphere bacterial community variation among control (blue points) and neonicotinoid-treated (pink 
points) samples is masked by the effects of host species (A) and time (B). While in soil (C), the bacterial communities vary among control (green points) and neonicotinoid-treated (red points) samples. Ellipses are shaded based on treatment (blue for control and yellow for neonicotinoid-treated samples) and represent a $95 \%$ confidence level.

A)

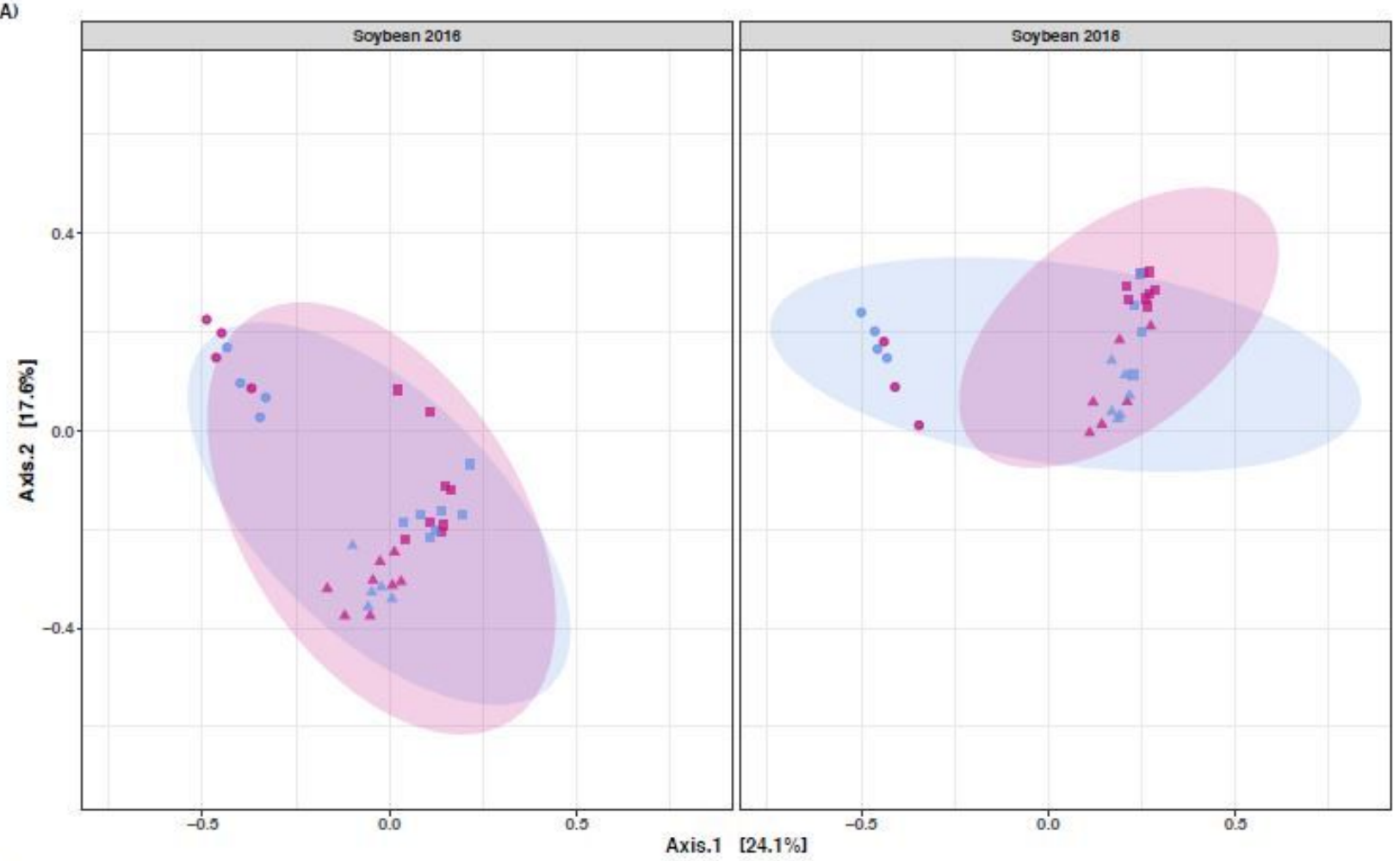

B)

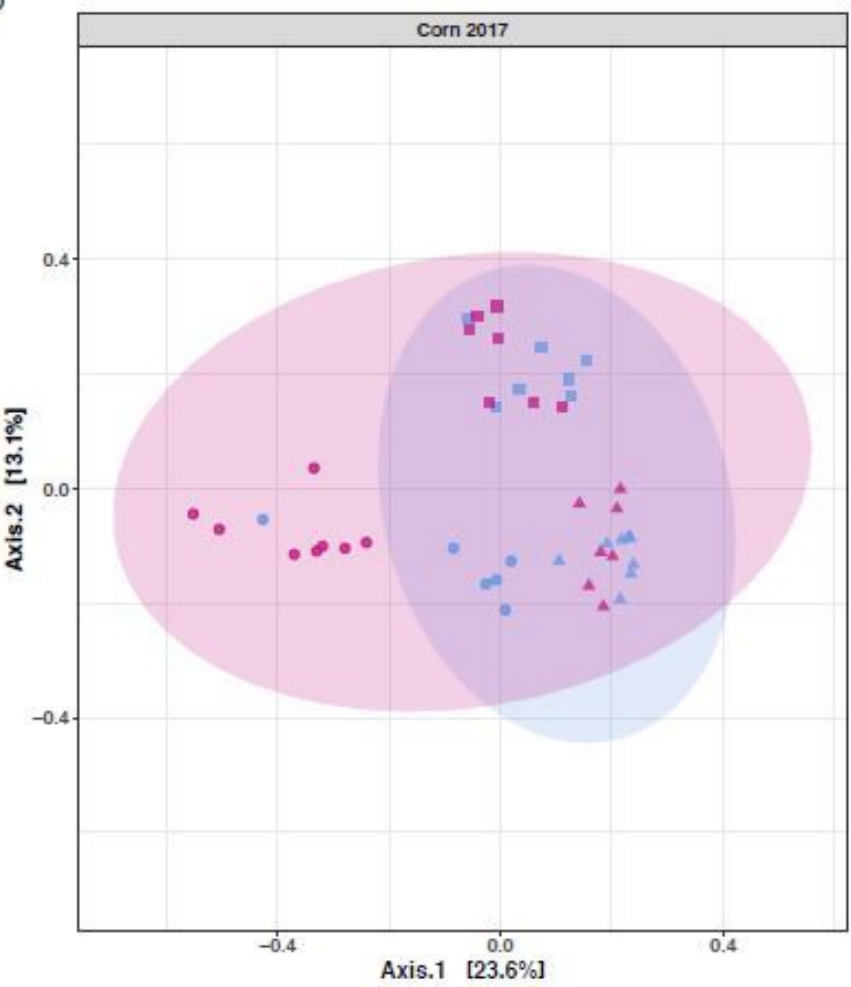

Treatment ellipses

Control

Month \& Treatement

Neonicotinoid-treated

- July - Control

- July - Neonicotinoid-treated

August - Control

August - Neonicotinoid-treated

September - Control

September - Neonicotinoid-treated

\section{Figure 3}


Soybean and corn phyllosphere bacterial community composition variations in response to neonicotinoid seed treatment and year. Principal coordinate analysis ( $\mathrm{PCOA}$ ) on Bray-Curtis dissimilarities illustrates the phyllosphere bacterial variation individually for each host species and year of rotation in L'Acadie, Quebec, Canada: A) soybean (left: year 2016; right: year 2018) and B) corn (year 2017). The shapes of the points represent the month and the colors show the treatment. Ellipses are shaded based on treatment (blue for control and pink for neonicotinoid-treated samples) and represent a 95\% confidence level.

A)
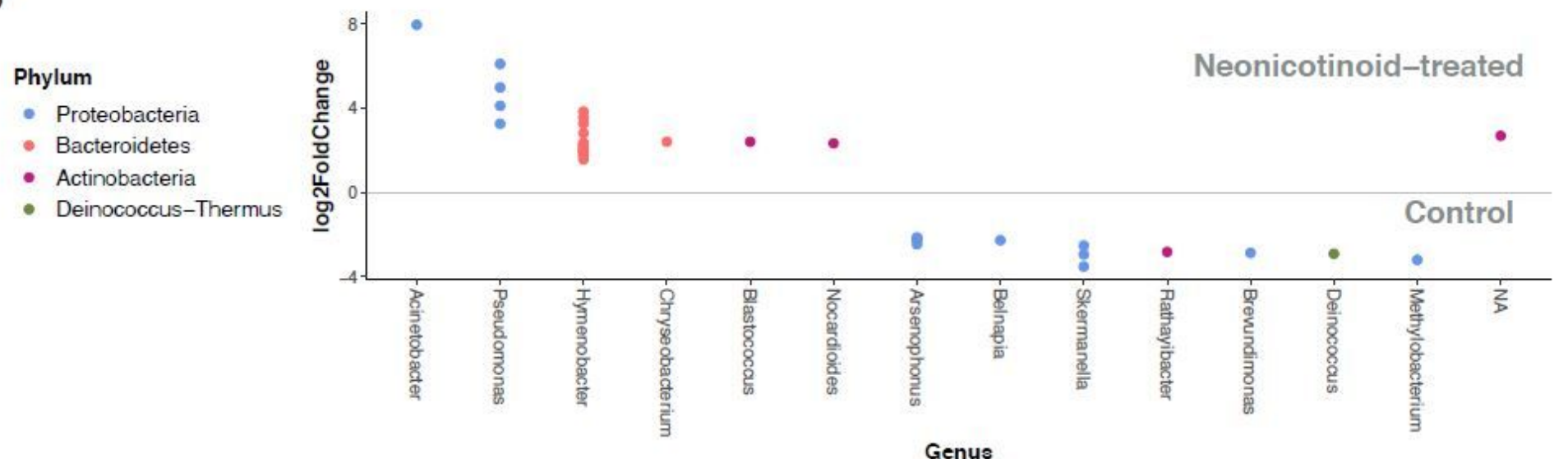

B)
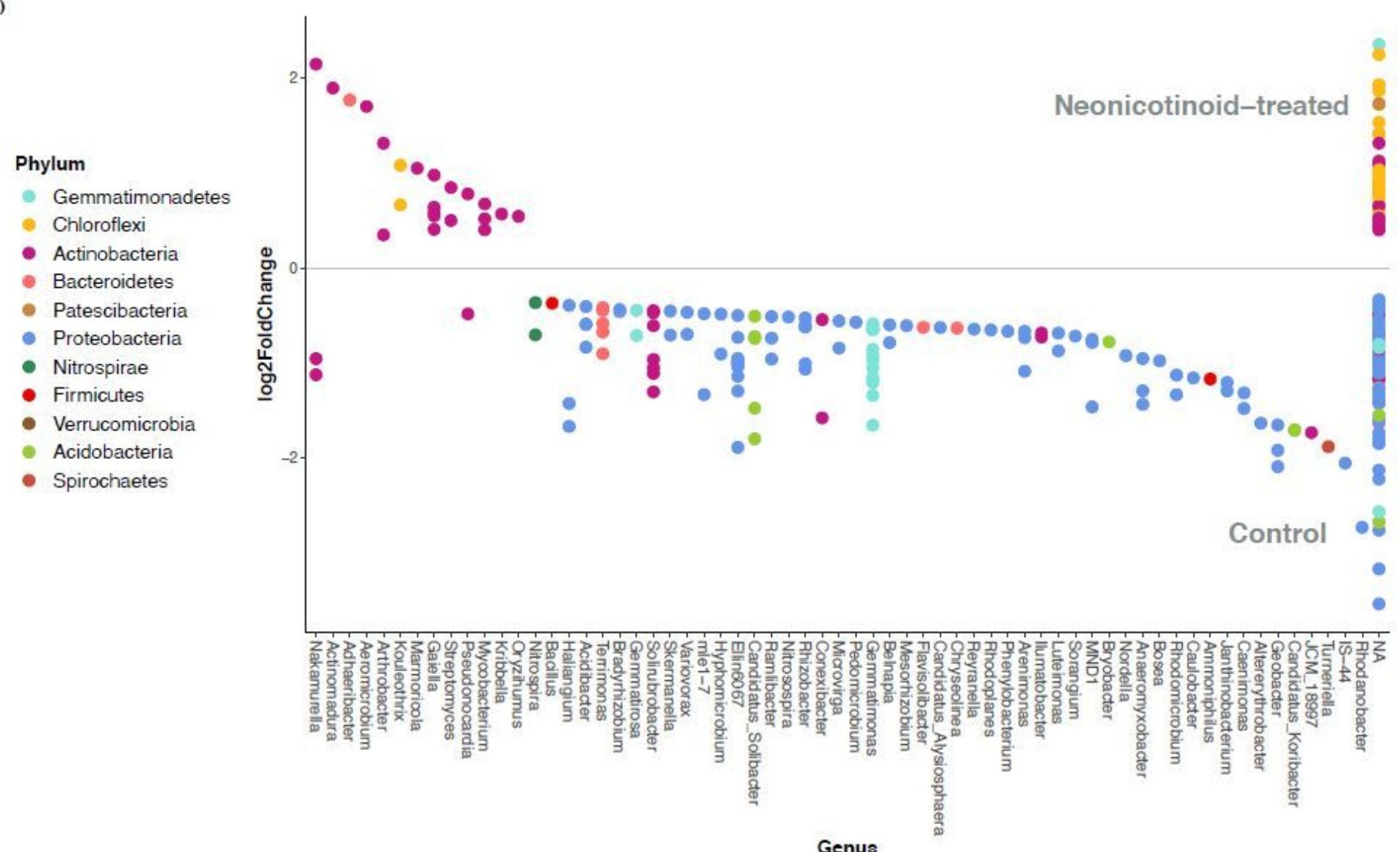

Figure 4

Phyllosphere and soil bacterial taxa (phyla and genera) associated with control and neonicotinoid seed treatment. Differential expression analysis of sequence data (DESeq2) illustrates the bacterial ASVs that 
are significantly differentially abundant (adjusted $\mathrm{P}<0.05$ ) between control and neonicotinoid-treated samples of soybean and corn phyllosphere (A) and soil (B) in a three-year rotation in L'Acadie. Each point represents one ASV related to a genus on the x-axis, and its color shows the phylum it belongs to. The ASVs on the top of each graph (log2FoldChange $>0$ ) are associated with the neonicotinoid-treated samples, while the others $(\log 2$ FoldChange $<0)$ are related to the controls.

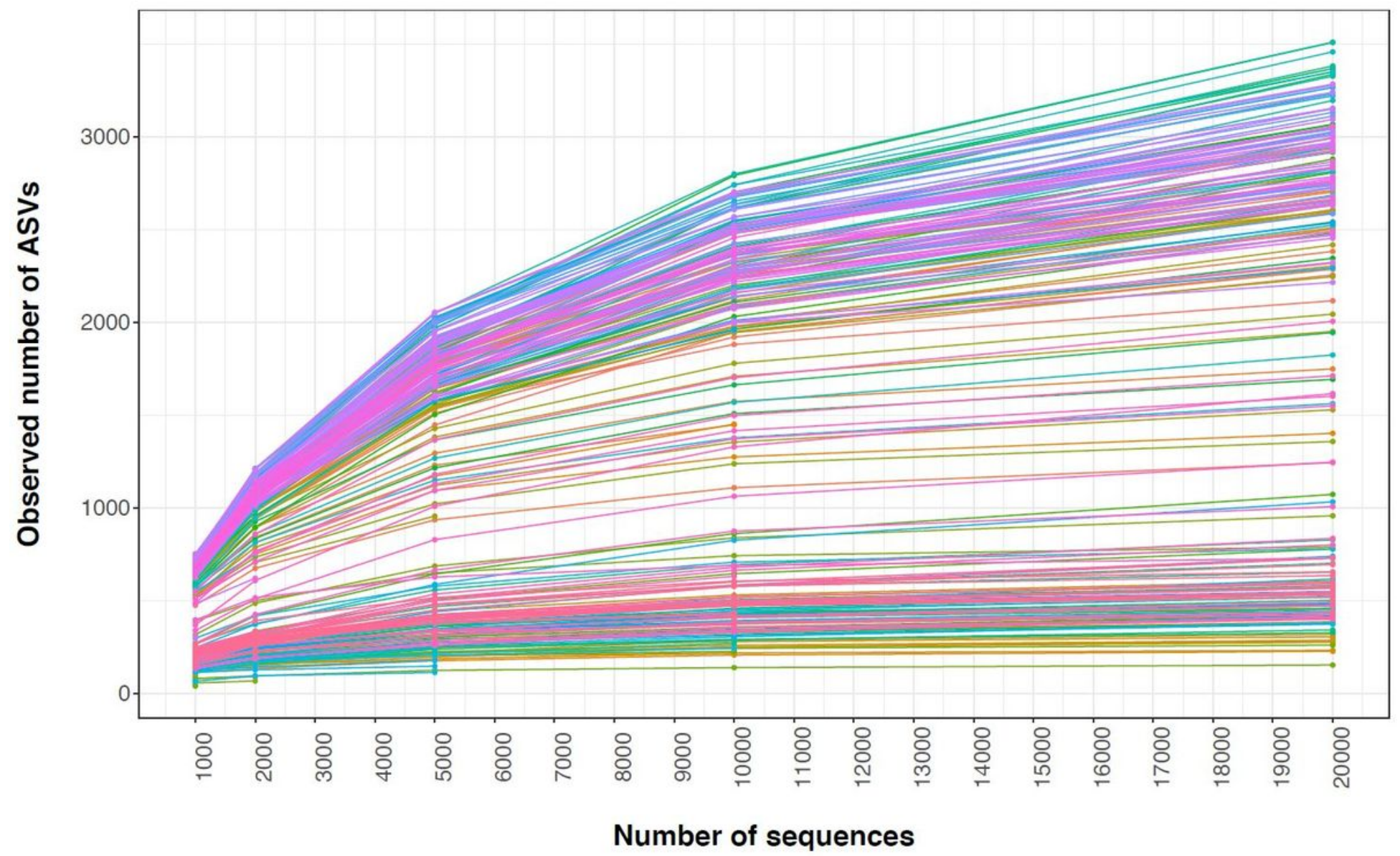

\section{Figure 5}

Rarefaction curves of the phyllosphere and soil bacterial ASVs. Rarefaction curves are shown for all the phyllosphere and soil samples according to the observed ASVs richness. Each line and color represent one sample. The sequencing coverage (x-axis: number of sequences) is 20,000 reads with cutoffs at $1,000,2,000,5,000$ and 10,000 reads.

\section{Supplementary Files}

This is a list of supplementary files associated with this preprint. Click to download.

- ParizadehMsep2020AddFileSuppTab3.xlsx

- ParizadehMsep2020AddFileSuppTab2.xIsx

- ParizadehMsep2020AddFileSuppTab1.xlsx

- ParizadehMsep2020AdditionalFile.pdf 